NBER WORKING PAPER SERIES

\title{
TOWARD AN UNDERSTANDING OF THE DEVELOPMENT OF TIME PREFERENCES: EVIDENCE FROM FIELD EXPERIMENTS
}

\author{
James Andreoni \\ Michael A. Kuhn \\ John A. List \\ Anya Samek \\ Kevin Sokal \\ Charles Sprenger \\ Working Paper 25590 \\ http://www.nber.org/papers/w25590 \\ NATIONAL BUREAU OF ECONOMIC RESEARCH \\ 1050 Massachusetts Avenue \\ Cambridge, MA 02138 \\ February 2019
}

We thank the Kenneth and Anne Griffin Foundation and the National Institutes of Health (NIH) grant 5R01DK114238 for funding this project. Andreoni also acknowledges the financial support from the National Science Foundation, Grant SES-165895. We thank participants at the AEA meetings and Nadia Chernyak for helpful comments. We thank the directors, principals and staff at the Chicago Heights Early Childhood Center and Illinois School District 170 for accommodating the data collection process. We thank Edie Dobrez, Jennie Huang, Phuong Ta, Kristin Troutman, Andre Gray and our staff of assessors for valuable research assistance. This research was conducted with the approval of the University of Chicago and University of Southern California Institutional Review Boards. The views expressed herein are those of the authors and do not necessarily reflect the views of the National Bureau of Economic Research.

NBER working papers are circulated for discussion and comment purposes. They have not been peer-reviewed or been subject to the review by the NBER Board of Directors that accompanies official NBER publications.

(C) 2019 by James Andreoni, Michael A. Kuhn, John A. List, Anya Samek, Kevin Sokal, and Charles Sprenger. All rights reserved. Short sections of text, not to exceed two paragraphs, may be quoted without explicit permission provided that full credit, including $(\mathcal{O}$ notice, is given to the source. 
Toward an Understanding of the Development of Time Preferences: Evidence from Field Experiments

James Andreoni, Michael A. Kuhn, John A. List, Anya Samek, Kevin Sokal, and Charles Sprenger

NBER Working Paper No. 25590

February 2019

JEL No. C9,C93,D03

\section{ABSTRACT}

Time preferences have been correlated with a range of life outcomes, yet little is known about their early development. We conduct a field experiment to elicit time preferences of over 1,200 children ages 3-12, who make several intertemporal decisions. To shed light on how such primitives form, we explore various channels that might affect time preferences, from background characteristics to the causal impact of an early schooling program that we developed and operated. Our results suggest that time preferences evolve substantially during this period, with younger children displaying more impatience than older children. We also find a strong association with race: black children, relative to white or Hispanic children, are more impatient. Finally, assignment to different schooling opportunities is not significantly associated with child time preferences.

James Andreoni

Department of Economics

University of California, San Diego

9500 Gilman Drive

La Jolla, CA 92093-0508

and NBER

andreoni@ucsd.edu

Michael A. Kuhn

Department of Economics

1285 University of Oregon

Eugene, CA 97403

mkuhn@uoregon.edu

John A. List

Department of Economics

University of Chicago

1126 East 59th

Chicago, IL 60637

and NBER

jlist@uchicago.edu
Anya Samek

Center for Economic and Social Research

University of Southern California

635 Downey Way

Los Angeles, CA 90089

anyasamek@gmail.com

Kevin Sokal

University of Chicago

sokal@uchicago.edu

Charles Sprenger

University of California, San Diego

Rady School of Business

9500 Gilman Drive

La Jolla, CA 93093

c.sprenger@gmail.com 


\section{Introduction}

The rate of time preference as elicited in the laboratory is strongly associated with a range of life outcomes, including health status, educational attainment, and labor market earnings (Golsteyn et al., 2014). ${ }^{1}$ Among children and adolescents, higher rates of impatience have been linked to a greater number of disciplinary referrals at school, lower high school completion rates, and more money spent on alcohol and cigarettes (Castillo et al., 2011; 2015; Sutter et al., 2013). In addition, impatient children are more affected by incentives than their patient counterparts (Oswald and Backes-Gellner, 2014). ${ }^{2}$ Therefore, how intertemporal preferences form at an early age, and how they interact with the environment, have direct policy implications.

This paper makes three overarching contributions to our understanding of the development of time preference. First, we design and implement a time preference elicitation task in which children ages 3-12 years old make a series of choices between receiving smaller amounts of candy at the end of the day or larger amounts of candy on the next day. There is a growing literature seeking to understand how economic preferences, such as time preferences, form at an early age. Yet the assessment of children's preferences is still in its infancy and a consensus is yet to form about best methods. We simplify the elicitation tasks typically used with adults and adjust the incentives to make the measures developmentally appropriate and incentive-compatible for the children in our sample. ${ }^{3}$

\footnotetext{
${ }^{1}$ In related work among adults, time preferences predict health, smoking, drinking and drug abuse behaviors (Bradford et al., 2017; Chabris et al., 2008; Khwaja et al., 2006; Weller et al., 2008), demand for medical screening tests or vaccines (Picone et al., 2004; Chapman and Coups, 1999) and take up financial education programs (Meier and Sprenger, 2013).

${ }^{2}$ In a related paper, Courtemanche et al. (2015) find that impatient adults are more sensitive to food price changes and exhibit the largest weight gain when food prices fall.

${ }^{3}$ Another advantage of our measure with children is that it might be a 'purer' measure of time preference than most of the literature presents with adult subject pools. One can think of this contribution in terms of measuring risk posture. Conventional expected utility theory recognizes the important effects of background risk on risk attitudes measured on the current choice. Harrison et al. (2007) show that background risk is important empirically, in that they find their subjects are considerably more risk averse when background risk is introduced. This result suggests the import of understanding the complete portfolio of risk the agent holds when making their choices. Similar reasoning should hold in standard models of time preference and their measurement. Provided that our subjects did not have material
} 
Our second contribution is exploring the correlates of time preferences. An advantage of this paper relative to prior work is that our dataset is very comprehensive. We have data on child demographic background (age, gender, race) and household characteristics (parents' educational attainment, household income). We go beyond these basic variables to collect detailed data on child cognitive and executive function skills via a rigorous skills assessment. We also collect data on a sub-set of the children's parents, which allows us to evaluate whether child time preferences are associated with their parents' time preferences. This lends insights into the origins of time preferences. Related work has explored the association of parents and family background with risk preferences (Alan et al., 2014), competitiveness (Almås et al., 2015) and other-regarding preferences (Bauer et al., 2014; Wilhelm et al., 2008).

We find that time preferences evolve significantly as children age, with younger children displaying more impatience than older children. This is in line with related work that finds a similar association with age (Bettinger and Slonim, 2007; Angerer et al., 2015; Deckers et al., 2015; Sutter et al., 2015). We also find a strong association with race: black children are significantly more impatient than white or Hispanic children, even while controlling for socio-economic status, cognitive skills and executive function skills. Only one other paper has had been able to explore this race relationship, and it found a similar association for adolescents (Castillo et al., 2011). Studying the associations of time preferences with race is important since - given that time preferences predict academic outcomes - it may help us understand the origins of the academic achievement gap.

We do not observe a correlation between preferences of parents and their children. We might have expected such a correlation due to genetics or social learning. However, the results in the related literature on the inter-generational transfer of time preferences are also mixed. Kosse

background temporal risk, they should not be subject to this issue. As far as we are aware, however, the literature has not provided estimates of how background temporal profiles affect current choices. 
and Pfeiffer $(2012,2013)$ do find associations of time preferences of preschool children and their parents, while Bettinger and Slonim (2006) do not find an association with children ages 5-16 and their parents. Researchers also find some support for a link between future orientation of parents and young adult children (Webley and Nyhus, 2006; Brown and Van der Pol, 2015). Understanding the associations of time preferences of parents and children is important in light of the recent interest in investing in parents as a policy tool for human capital accumulation (Fryer et al., 2015).

Our third contribution is to evaluate the causal influence of early childhood education on child time preferences. For this evaluation, we take advantage of the Chicago Heights Early Childhood Center (CHECC) study (Fryer et al., 2015; 2018). Children in our study are participants in CHECC, which randomly assigned children and parents from Chicago Heights, Illinois and surrounding areas to 1) a free, high-quality preschool program,2) a parenting program in which parents were taught how to implement components of the preschool curriculum at home, or 3) to a control group that did not receive an intervention. We hypothesized that children randomized to CHECC preschool might become more patient since they were exposed to an environment and activities that promoted patience, such as a structured preschool day, turn-taking and modeling patience. The parenting program at CHECC also provided tools that parents could use to teach patience - such as a unit on self-regulation - hence, we hypothesized that children exposed to CHECC parent programs might also become more patient than children in the control group.

Our evaluation of CHECC joins a very small literature aimed at studying the causal impact of education programs on time preferences. Alan and Ertac (2014) found that random assignment to a program aimed at helping third and fourth grade children imagine their future selves increased patience relative to children assigned to a control group. Lührmann et al. (2014) found that random assignment of adolescents to a financial education program increased time consistency relative to 
those assigned to a control group. Unlike these studies, our early childhood interventions do not focus specifically on time preferences and are broader in scope. We believe that it is important to learn whether "standard" early childhood programs, designed to impact cognitive abilities, also affect time preferences. Moreover, we explore time preference development in very early childhood, which is a critical period of non-cognitive skill development (Heckman, 2000). Our study also speaks to the literature that uses early childhood interventions to understand the impact on the academic achievement gap, such as High/Scope Perry Preschool and the Abecedarian project (Schweinhart, 1993; Campbell et al., 2002). The evaluation of High/Scope Perry and Abecedarian did not consider time preferences as we do, and the sample size of these programs was significantly smaller than ours.

In contrast to our hypotheses, we do not find a statistically significant impact of CHECC programs on time preferences. This is true both immediately after the intervention as well as a few years after the end of the intervention. By contrast, another paper evaluating CHECC found an impact of the preschool and parent programs on fairness and efficiency concerns but not on selfishness (Cappelen et al., 2016). The fact that our early interventions, which were quite broad, did not lead to durable changes in time preferences suggests that such preferences may be difficult to change with education programs for 3-5 year-olds. An important caveat is that we have substantial attrition in our analysis sample.

The population we study is also policy relevant. By virtue of being from CHECC, the households in our sample are of generally low SES. Understanding how time preferences form may be even more important among low SES children, since they are the ones most likely to exhibit impatience (Deckers et al., 2015; Schildberg-Hörisch et al., 2014), and may therefore benefit the most from policy interventions. Eckel et al. (2010) note that results from undergraduate students do not always generalize to children or other populations. Finally, our study includes a much 
broader age range than most other papers (for example, Castillo et al., 2011; Sutter et al., 2013 focus on adolescents, while Kosse and Pfeiffer, 2012; 2013, Falk and Kosse, 2016 focus only on preschoolers).

In what follows, Section 2 discusses our time preference elicitation, summarizes our data and provides a discussion of the strengths and weaknesses of our measure. Section 3 discusses the correlates of time preferences, including age, race, and parent time preferences. Section 4 explains CHECC in more detail and provides the causal evidence. Section 5 concludes.

\section{Time Preference Elicitation}

\subsection{Experimental Design and Procedures}

The experiment was conducted in 4 waves. In the first three waves of the experiment (201011, 2012 and 2013), families brought their children to the CHECC center outside of school time to participate. Participants did not know what the experiments were about when they signed up, and participation was voluntary. Participation took approximately 30 minutes and parents received approximately $\$ 25$ for their participation. In the last wave (2017-18), we conducted the experiments during school and children were pulled from class to participate individually. The sessions differed in their implementation, as described below. Most children participated 1-2 times between 2010 and 2018 .

The basic experimental design of the time preference elicitation task followed a multipleprice list format with 3-4 decisions (Coller and Williams, 1999). Eliciting time preferences in this way has been shown to be correlated with life outcomes of adolescents and adults (e.g., Castillo et al., 2011). Children made a series of decisions in which they were asked to choose between a smaller amount of rewards on the day of the experiment at the end of the day ("at the end of the day TODAY"), and a larger amount of rewards on the day after the experiment ("at the end of the 
day TOMORROW"). Only one of the decisions "counted" for payment, and this was randomly selected at the end of the experiment. ${ }^{4}$ In the earlier sessions, rewards from the relevant decision for payment were placed in paper bags with the date of payment on them and were given to the child's parents with a note providing instructions for when to give the child the candies. We also verbally explained to parents when to give the rewards to the child. ${ }^{5}$ In the 2017-18 wave that was conducted during school time, we gave bags of rewards to teachers to put in child backpacks on the dates that children selected. Table 1 summarizes the series of decisions in each experimental session.

\section{[ TABLE 1: CHILD EXPERIMENT DESIGN ]}

For most children, the experiment was conducted one-on-one with a trained experimenter and each decision was accompanied by physical containers holding the number of rewards that would be earned by the child for each alternative. The rewards were always candies in waves 201011, 2012 and 2013; and were the choice of different candies or prizes in 2017-18. Some of the older children (ages 6-12) in the 2010-11 wave participated in small groups whereby children circled pictures of candies on their record sheets in private while experimenters walked around to assist. The age overlap in procedures allows us to control for differences in implementation approach.

\footnotetext{
${ }^{4}$ For children ages 3-5, the random selection was done in the following way. Children were told that at the end of the session, one of their decisions would be selected at random as the 'decision that counts.' The 'decision that counts' was selected by having the child close his or her eyes and select one of X containers in the bin, each of which held the candy and time for the candy to be given to the child for one of the decisions. For children ages 6-12, the random selection was done via bingo cage at the front of the experiment room.

${ }^{5}$ The potential for parents to not follow through on the experimental timing, and the child's expectation thereof, presents a potential confound in our study. If parents are likely to give their children the candy as soon as possible, children should choose the most candy possible and, hence, appear quite patient in our study. This prediction is in contrast to aggregate behavior, which exhibits substantial impatience.
} 


\subsection{Data}

Table 2 provides a summary of the observations in our dataset, by data collection wave. A total of 1,265 individual children participated in our experiments, with 926 participating in only one wave, 307 participating in two waves and 32 participating in 3 waves. This gives us a total of 1,636 observations, spanning ages 3 through 12 (Mean=6.95, S.D.=2.64). About half the observations were girls (50.03\%). In line with the population of Chicago Heights, IL, our sample is highly diverse, with $35.16 \%$ black and $55.77 \%$ Hispanic observations. The households are relatively low income: $28.42 \%$ of observations come from a household with an annual income of $\$ 0-\$ 15,000$ and $27.20 \%$ come from a household with an annual income of $\$ 16,000-\$ 35,000$. About $17 \%$ of the observations have mothers who do not have a high school diploma, while $35 \%$ have a high school diploma or some college education and $22 \%$ have a college degree.

\section{[ TABLE 2: SUMMARY OF OBSERVATIONS ]}

Figure 1 provides a histogram of the proportion of patient decisions (giving up fewer rewards today to choose more rewards tomorrow) across all sessions. It is notable that a large proportion (28.97\%) of children always select the earlier, smaller reward while a small proportion (12.04\%) always select the later, larger reward.

\section{[ FIGURE 1: HISTOGRAM OF CHILD DECISIONS ]}

We also find that a sizable fraction of the children exhibit non-monotonicities in their choices, preferring a larger, later number of rewards to a smaller, sooner number, and subsequently preferring an even smaller, sooner number of rewards to the aforementioned later, larger number. The overall proportion of children displaying such non-monotonicities is $40.63 \%$. However, $68.87 \%$ of the 965 children who are not always impatient or always patient are non-monotonic. Despite the high frequency of non-monotonicities, as displayed in Figure 2, we do observe that in the aggregate children are more likely to be patient when the cost of being impatient is high (i.e., 
when the difference between the earlier and later rewards is largest), a finding that is also observed in Lemmon and Moore (2007) for children aged 4-5.

\section{[ FIGURE 2: PROPORTION PATIENT CHILDREN BY DECISION \& WAVE ]}

\subsection{Discussion}

Our time preference elicitation methodology is similar to that used with adults in experimental economics, and is in line with related work in developmental psychology that uses children as young as age 2-3 to study future orientation (Schwarz et al., 1983; Lemmon and Moore, 2007; Garon et al., 2012). Our elicitation is similar to Sutter et al. (2015), who conduct time preference experiments with Kindergarteners and use 1 choice of 1 reward today versus 2 rewards the next day. Different from Sutter et al. (2015), we used a series of questions with varying interest rates rather than just one question. Our elicitation is also similar to one of the elicitations in Angerer et al. (2015), who include children ages 6-11 in their experiments and use a series of questions in which children choose between 2 tokens (which can be exchanged for candy or prizes) at the end of the experimental sessions versus 3, 4 or 5 tokens in 4 weeks. Our elicitation is also similar to Bettinger and Slonim (2007), who include children as young as 5 in their experiments, but the series of choices is delayed further in time - by 1-2 months rather than by 1 day as in our study. We believe that the shorter delay is more appropriate, since in developmental psychology, a 1-day delay is sometimes considered a "long" delay condition for this age group (Schwarz et al., 1983).

Since the high degree of non-monotonicities of the children will not allow us to calculate or estimate a conventionally meaningful discount rate, in our analysis we use two non-parametric measures of time preference. The first measure is the total number of patient decisions (standardized by session). The second measure is a binary variable indicating whether a child is always impatient or not. Despite the non-monotonicities, we believe the elicitation task is still 
useful since it allows us to categorize children with narrower bracketing than a single question measure.

A different method for eliciting the impatience level of young children is Mischel's “marshmallow” paradigm (Mischel et al., 1972; Mischel and Moore, 1973; Mischel et al., 1989). In this experiment, preschool aged children are seated in front of a treat and are offered the option to either eat the treat, or to wait to receive double the amount. This paradigm is commonly used in the developmental psychology literature (e.g., Karniol et al., 2011) and was also used by Kosse and Pfeiffer $(2012,2013)$ to study intergenerational transfer of impatience from mothers to their preschool-aged children. Developmental psychologists use the marshmallow paradigm because unlike the "choice" paradigm, it puts children in a situation where they must overcome their frustration and inhibit their desire to eat the treat in front of them for a prolonged period of time (Shoda et al., 1990). In the choice paradigm, children view the reward only briefly before making their decision, and therefore are not in a prolonged situation where they must exercise inhibitory control. In our study, we used the choice paradigm as our primary measure because we believe that the choice paradigm, and not the marshmallow paradigm, is most similar to the time preference elicitations that economists are interested in with adults.

A subset of the younger children in our study also participated in the marshmallow paradigm at different points in time than the main experiment ( 881 observations with 799 children, mean age $=4.79$, min of 3.2 and $\max$ of 7.6). In different waves, we gave children either 5,8 or 15 minutes wait time before the experimenter returned and doubled their treat. Castillo et al. (2018) use the time preferences data we report on here, the marshmallow paradigm and a number of other measures not reported here to study associations of skills at an early age and demonstrate that the marshmallow paradigm is not correlated with the choice paradigm. They also show that the time preferences measured at an early age using our paradigm are associated with disciplinary referrals 
several years later. In this paper, in the proceeding sections we use the marshmallow paradigm as an alternative measure of impatience to study the robustness of our findings.

A concern when evaluating time preferences with either children or adults is that they are confounded with risk preferences (Andreoni and Sprenger, 2012). Participants may choose an immediate reward rather than delaying the reward because they are risk averse and prefer a certain outcome. We address this in two ways. First, all of our sooner, smaller rewards have a front-end delay since children receive them "at the end of the day today." This helps to equalize any perceived risk across payments. Second, we also directly elicit risk preferences during the session, and we control for risk preferences in our analyses. The risk preference elicitation in the 2010-11 wave features the choice of a number of pencils from a jar, whereby one of the pencils has a red mark on the bottom. Children get to keep all the pencils, unless one of the pencils has a red mark. If any pencil has a red mark, children must return all the pencils. This elicitation is summarized in greater detail in Andreoni et al. (2009). The risk preference elicitation in the remaining waves features a multiple price list of choices between smaller, certain rewards and the different probabilities of winning larger rewards. This elicitation is summarized in greater detail in Castillo et al. (2018).

\section{Correlates with Time Preferences}

\subsection{Age-Related Changes}

Figure 3 provides a histogram of the ages in our sample and Figure 4 provides the trends of patient decisions and consistency with age. Using the proportion of patient decisions as our main measure, we find a slight decline in patience from about 3 years old to 5 years old, and a larger increase in patience from 5 years old to 12 years old. Figure 3 also graphs the proportion of decisions that are "all immediate" or "all delayed." About $25 \%$ of decisions among 3-year-olds are 
"all immediate", and this number increases to nearly $50 \%$ for 5 -year-olds and drops to under $10 \%$ for children age 9 and up. Only about 10-20\% of decisions at any age are "all delayed." Figure 3 also displays the proportion of decisions that are monotonic, including only those decisions with at least one switch point. We see that for children who have at least one switch point, monotonicity increases from about $20 \%$ of observations among 3 year olds to about $30 \%$ of observations among 12 year-olds. ${ }^{6}$

\section{[ FIGURE 3: HISTOGRAM OF AGES ]}

\section{[ FIGURE 4: PATIENT AND MONOTONIC DECISIONS, BY AGE ]}

The standard errors in the proportion patient are largest at the extremes of our age range. The standard errors are smaller in the center of the age distribution, where we see a clear positive relationship between age and patience that is statistically significant in regression analyses.

Interestingly, we see some indication that children become less patient from age 3 to 5 . We attribute this to the possibility that some 3 year-olds have not yet understood the concept of "tomorrow." These children might choose the preferred, larger reward and not anticipate that they will have to wait for it. An indication that 3 year-olds might have difficulty with predicting the future is presented in Busby and Suddendorf (2005), who find that only $30 \%$ of 3 year-olds and $60 \%$ of $4-5$ year-olds were able to correctly predict events that would happen tomorrow.

A confound with studying the evolution of time preferences with age is that other variables are also changing during this time. For instance, there are increases in cognitive abilities during this same time period. In our analysis, we can control for cognitive abilities, as measured by a score on a reading, writing and math assessment administered within a year of the experiments. We can also control for executive functions, as measured by an assessment of inhibitory control,

\footnotetext{
${ }^{6}$ A similar plot of monotonicity that does include the "all now" or "all later" data results in a decrease in monotonicity with age. That is partly because many more young children prefer "all now" than older children.
} 
working memory and attention shifting. ${ }^{7}$ Finally, we can control for risk preferences, which may also change during this time period.

Table 3 provides regressions with proportion of patient decisions (standardized by session, specifications 1-4) and immediate choices (binary, specifications 5-8) as dependent variables, using all the observations and clustering at the individual level. All specifications feature wave year controls. In specifications (2) and (6) we add socio-economic characteristics, in specifications (3) and (7) we add controls for cognitive ability and executive functions, and in specifications (4) and (8) we add the risk preference control. The coefficient on age (row 1) is positive (between 0.05 and 0.09 ) and statistically significant in specifications 1-2, and negative (between 0.02 and 0.03 ) and statistically significant in specifications 5-6, providing support for the age trend displayed in Figure 3. Appendix Table A.1 includes an age squared variable and shows a weaker correlation between age and time preferences. However, the marginal effects do suggest that the relationship between age and the proportion of patient decisions in these specifications is predicted to be negative until ages 4-6, and positive thereafter.

\section{[ TABLE 3: PREDICTORS OF CHILD TIME PREFERENCES ]}

Studying the cross-sectional variation in time preferences is important because time preferences are predictive of later life outcomes. But studying the evolution of time preferences by age is itself interesting since children make decisions that affect their future selves (such as choice to complete homework, or show up to school). The age profile of children's patience illustrates the degree to which older children will disagree with the decisions their younger selves

\footnotetext{
${ }^{7}$ For participants below second grade, the cognitive abilities are measured by four sub-tests of the Woodcock-Johnson III and the Peabody Picture Vocabulary III test. The executive functions are measured using Blair and Willoughby's tests of working memory, attention shifting and inhibitory control. More details about each test are provided in Castillo et al. (2018), which goes into detail on each sub-test. For participants in third grade and above, cognitive abilities are taken from the NWEA MAP test administered by the state of Illinois each year, which is a personalized assessment that measures individual student growth using a cross-grade scale. Executive functions are taken from a separately administered assessment using the working memory and executive function and attention sub-tests of the NIH Toolbox.
} 
made. Further, many interventions are geared at this age range, and understanding the impact of these interventions on children may involve understanding where they are in the evolution of their time preferences. For example, the evolution of time preferences we see here may suggest that younger children would do better with immediate incentives while older children may accept delayed incentives as part of an intervention.

\subsection{Correlates with Race}

We next consider associations between child demographic and socio-economic characteristics on child time preferences. We find that child race plays a statistically significant role in the level of patience. Black children make a higher proportion of impatient decisions and are more likely to make all impatient decisions relative to Hispanic children (see all specifications in Table 3 - coefficient estimates are between -0.16 and -0.27 in specifications $1-4$, with p-values $<0.05)$. In Appendix Table A.2 we also include an interaction term between race and age. The interaction terms for the time preferences outcome variable are not statistically significant in most specifications, suggesting that the associations with race are similar across all ages in our sample. Our finding that black children are more impatient is in line with Castillo et al. (2011), who find that among 13-14 year-old children, black children are more impatient than non-black children. Our sample includes children of ages 3-12, showing that this heterogeneity appears at even very young ages.

\subsection{Correlates with Parent Time Preferences}

The parent experiment included 16 decisions from two multiple-price lists, where parents chose between amounts of $\$ 6$ to $\$ 20$ earlier versus $\$ 20$ later. For the first 8 decisions the earlier time was today and the later time was 5 weeks from today, and for the remaining 8 decisions the 
earlier time was 5 weeks from today and the later time was 10 weeks from today. Only one decision was randomly paid out.

The parent time preference experiments were carried out in two waves: once in 2012, and again in 2017-18. A total of 643 adult caregivers completed the parent preference elicitation tasks (262 in 2012 and 381 in 2017-18). 501 participated only once and 71 participated two times. Using the original CHECC registration data, we identified 444 (77.62\%) as the mother, $91(15.91 \%)$ as the father, and $36(6.29 \%)$ as another caregiver (usually this is the grandmother or relative that lives with the child). For parent time preferences, we simply calculate the proportion of patient decisions out of 16 (a histogram of these outcomes is available as Appendix Figure A.2). In case of households that had multiple parents participating, we averaged the time preferences of both caregivers for the analysis. Since only a sub-set of parents completed the voluntary questionnaire on socio-economic status, and a different (smaller) sub-set participated in the voluntary time preference experiments, we consider both variables in separate regressions.

Table 4 presents regression results including the controls for parent time preferences. We do not find strong associations of parent time preferences with child time preferences. The coefficients on "Parent Time Pref." are small and even change signs across specifications, with all p-values above 0.10 . Note that in Table 4 we continue to see the effects of age and race that we described in sub-sections 3.1 and 3.2. As a robustness check, Appendix Table A.3 replicates this regression using only mothers, finding qualitatively similar results (no effect of mother's time preferences, and continued effects of age and race as described in sub-sections 3.1 and 3.2).

While parent preferences do not predict child preferences, as shown in Appendix Table A.4, which regresses demographic characteristics of the child on the parents 'time preferences, we find that parents of black children are significantly more impatient than parents of Hispanic or 
white children. This is in line with the race result for children presented in sub-section 3.2, and suggests a persistence of measured time preferences into adulthood.

\section{[ TABLE 4: PREDICTORS WITH PARENT CONTROLS ]}

\section{Impact of Early Childhood Interventions}

\subsection{Experimental Design}

Our participants were recruited from the Chicago Heights Early Childhood Center (CHECC) program. ${ }^{8}$ CHECC is a large-scale intervention study on the role of different early education programs on schooling outcomes of disadvantaged children conducted in 2010-2014 (Fryer et al., 2015; 2018). Households who participated in CHECC originated from the surrounding area of Chicago Heights, Illinois. Chicago Heights is an ethnically diverse (41\% African American, 34\% Hispanic) and generally low-income area (29\% of persons below poverty level, $\$ 18,121$ per capita money income). ${ }^{9}$ To support recruiting efforts, CHECC ran a local marketing campaign each year, which included direct mailings, automated phone calls to families with children enrolled in the district, and information booths at community events in and around the district. Program information was also distributed through district leadership staff in the school districts, and administrative assistants at schools were encouraged to collect and submit registration forms for CHECC.

The main goal of CHECC was to investigate the role of early childhood programs on educational attainment; therefore, households who signed up for the program were randomized each year (during four years 2010-2013) into one of several different treatment arms or to a control

\footnotetext{
${ }^{8}$ CHECC was called the Griffin Early Childhood Center (GECC) between 2010 and 2012, and was renamed to CHECC in 2012.

${ }^{9}$ Data from the United States Census http://quickfacts.census.gov/qfd/states/17/1714026.html
} 
group. ${ }^{10}$ A different set of treatments was tested in 2010 and 2011 and another set was tested in 2012 and 2013. The treatments are described below:

- Preschool-Literacy and Math (2010 and 2011): This was a free, full-day 9-month long preschool program that used the Literacy Express curriculum combined with a math component. The purpose of this curriculum was to teach academic skills like literacy and math.

- Preschool-Tools of the Mind (2010 and 2011): This was a free, full-day 9-month long preschool program that used Tools of the Mind curriculum. The purpose of this curriculum was to teach executive functioning skills.

- Parent Academy-Cash (2010 and 2011): This was a class that parents attended two times a month to learn how to teach to their children at home. Parents received \$100 in cash for attending each class, and earned additional cash rewards for completing homework assignments and for their child's performance on tests.

- Parent Academy-College (2010 and 2011): This was a class that parents attended two times a month to learn how to teach to their children at home. Parents received $\$ 100$ in cash for attending each class, and earned additional rewards for completing homework assignments and for their child's performance on tests. The additional rewards were deposited into an account they could access for their child's college (or other vocational, post-secondary) education.

- Preschool-CogX (2012 and 2013): This was a free, half-day preschool program with halfday of child-care, for 9 months. It also included a class that parents attended two times a

\footnotetext{
${ }^{10}$ The CHECC randomization followed a blocked approach. In each randomization, matched groupings of children were created based on gender, race (white, Hispanic or black), and age (within $1 / 2$ years). Then, each child in the grouping was randomly assigned to a treatment or control group. Children for whom matched groupings were not created were placed in the control group. In Fryer et al. (2018) only the matched pairs are used and the full sample is used as a robustness test, but in our analysis here we use the full sample.
} 
month to learn how to scaffold their children's learning at home. Parents received $\$ 50$ in cash for attending each class, but did not receive additional rewards. The curriculum used was $\operatorname{Cog} X$, which combines aspects of literacy, math, and executive functions and was developed by the PIs (Fryer et al., 2018).

- $\quad$ Kinderprep (2012 and 2013): This was a free, half-day preschool program during the two months of summer prior to the start of Kindergarten. It also included a class that parents attended two times a month to learn how to scaffold their children's learning at home. Parents received $\$ 50$ in cash for attending each class, but did not receive additional rewards. The curriculum used was $\operatorname{Cog} X$, which combines aspects of literacy, math, and executive functions and was developed by the PIs (Fryer et al., 2018).

- Control group (all years): Children randomized to the control group did not receive any educational programming from us. This group was referred to externally as the Family Group and families were invited to family parties several times a year to minimize attrition. They also received cash incentives to participate in assessments.

Fryer et al. (2015) reports on the impact of the Parent Academy programs, while Fryer et al. (2018) reports on the impact of Preschool-CogX and Kinderprep on cognitive skills and executive functions. The authors find that Parent Academy primarily improved executive functions, while Preschool-CogX and Kinderprep primarily improved cognitive skills. The impact on cognitive skills faded out several years after the end of the programs.

In this paper, to investigate the impact of early education programs on time preferences, we use data from the 2012, 2013 and 2017-18 data collection waves since these were conducted after most children had the chance to participate in CHECC education programs. There are some caveats with the sample selection. In 2012 and 2013, we invited parents to participate in sessions 
by bringing children in during a non-school time and we did not attempt to recruit the full sample. Only $39.87 \%$ (815 of 2044) of children who had participated in a CHECC program were part of the time preference data collection (31\% - 284 of 921 in 2012 and $27.1 \%$ - 440 of 1,625 in 2013). This includes $46.62 \%$ of the Parent group, $50.47 \%$ of the Preschool group and $43.62 \%$ of the Control group.

We used a different strategy in the 2017-18 wave. Instead of relying on parents to bring in their children, in 2017-18, we collected data from all children who were attending one of the 9 schools in Chicago Heights Illinois School District 170. Data was collected during school. Therefore, by design we do not have data on children who were attending other school districts during this time period (data is available for $26.99 \%$ or 647 of 2208 of children). This includes $30.42 \%$ of the Parent group, $21.30 \%$ of the Preschool group and $29.64 \%$ of the Control group. However, if we believe that children did not move in and out of district due to CHECC treatment assignment - which they would have had no reason to do - then this attrition should not affect the results of our experiment.

Figure A.1 in the appendix provides a diagram that describes how children flow through the programs and the experimental waves. Table A.5 in the appendix provides summary statistics comparing participants in the 2012-13 waves to non-participants from CHECC who would have been eligible, and participants in the 2017-18 wave who were in District 170 with non-participants from CHECC who were not in District 170. We find that in the 2012-13 waves, experiment participants were similar to non-participants on race, gender, mother's education and pre-assessed cognitive ability (all p-values $>0.10$ ), and different from non-participants on age, income and preassessed non-cognitive ability (all p-values $<0.01$ ). We find that in the 2017-18 wave, participants were similar to non-participants on age, gender and pre-assessed non-cognitive ability and different from non-participants on race, income and mother's education. More participants in 
2017-18 were Hispanic than in the overall sample ( $\mathrm{p}$-value $<0.01)$ and fewer were black than in the overall sample ( $p$-value $<0.01$ ). These latter differences may have been expected because District 170 is located in an area with more Hispanic residents relative to areas where the rest of the sample resides, and the 2017-18 wave was limited to District 170 students.

It is important to delineate how this paper relates to other papers that have been published using the CHECC sample. Fryer et al. (2015) and Fryer et al. (2018) report on the impact of the programs on cognitive abilities and executive functions. Andreoni et al. (2018) reports on the evolution of risk preferences of CHECC children and of adolescents who participated in a separate intervention program. Cappelen et al. (2016) reports on the impact of the CHECC programs on fairness preferences. Unlike Andreoni et al. (2018) and Cappelen et al. (2016), we consider the impact of the programs on time preferences. Castillo et al. (2018) considers the associations of risk preferences, time preferences, social preferences, cognitive abilities and executive functions at an early age and evaluates the impact of these skills on disciplinary referrals several years later. Castillo et al. (2018) only use the time preferences (and other skills) collected at the beginning of the CHECC study, while in this paper we use all of the time preference measures collected throughout the CHECC study to understand the evolution of time preferences across ages. Several related papers also use small sub-samples of CHECC students to understand parental cheating behavior (Houser et al., 2016), parental charitable giving (Ben-Ner et al., 2017; Samek and Sheremeta, 2017), child charitable giving behavior (List and Samak, 2013; and List et al., 2018; Cowell et al., 2015; Cox et al., 2016), child competitiveness (Samak, 2013) and parent food choice (Sadoff and Samek, 2018). A paper has also been written about the test-retest reliability of executive function measures (Willoughby et al., 2017). 


\subsection{Treatment Effects}

Tables 5 and 6 show the impact of being randomly assigned to one of our interventions on time preferences, whereby Table 5 uses the 2012-13 waves of data and Table 6 uses the 2017-18 wave of data. The dummy variable "Preschool Dummy" refers to whether the child was randomized to any of the preschool programs (including the Kinderprep program), while the dummy variable "Parent Academy Dummy" refers to whether the child was randomized to any of the Parent Academies. In some specifications, we also control for SES and cognitive and executive function abilities at baseline (when children entered CHECC). In Appendix Tables A.6 and A.7 we perform the same analysis but disaggregating the Parent Academy and Preschool variables into each of the separate curricula treatment arms described in Section 4.1. To mitigate concerns of differential attrition, in Appendix Tables A.8 and A.9 we perform the same analysis but using inverse probability weighting by age, gender and race.

We do not see a strong association with randomization to one of the programs on child time preferences (all coefficients small - on the order of 0.01 and 0.03 -- and insignificant with $\mathrm{p}>0.10$ ), suggesting that perhaps time preferences are difficult to influence through general education programs such as ours. For example, specification (5) in Tables 5 and 6 provides treatment effects of the programs on the choice of "always now." We see that Preschool results in an insignificant $2 \%$ decrease in the probability of choosing "always now." We see that Parent Academy results in either an insignificant 2\% increase (Table 5, 2012-13 waves) or 5\% decrease (Table 6, 2017-18 wave) in the probability of choosing of "always now". The standard errors on these coefficients are 0.03 to 0.13 . By contrast, being black relative to Hispanic is associated with a $14 \%$ increase in the probability of choosing "always now." And, in the Cappelen et al. (2016) experiment that evaluated the impact of CHECC programs on fairness, being assigned to Parent 
Academy is associated with a $14 \%$ increase in the probability of choosing the efficient versus fair allocation of resources.

Note that race, but not age, continues to be associated with time preferences in Table 5. We speculate that age is not statistically significant in Table 5 because the 2013 wave includes only children ages 3-6 (a more narrow age range). We speculate that race is not statistically significant in Table 6 because the racial composition in the 2017-18 wave is predominately Hispanic since we collected data in one particular school district.

\section{[ TABLE 5: TREATMENT EFFECTS, 2013 WAVE ] \\ [ TABLE 6: TREATMENT EFFECTS, 2017-18 WAVE ]}

\section{Additional Analysis}

\subsection{Multiple Hypothesis Test Correction}

Tables 5-6 imply 5 different hypotheses are being tested, i.e., that time preferences evolve with age, and may differ when comparing boys and girls, black and white children, black and Hispanic children, and Hispanic and white children. It is thus important to adjust for the familywise error rate (e.g., see List et al., 2016). Holm-Bonferroni $p$-value correction yields continued statistical significance for the comparisons of black and Hispanic children in columns 3-5 of Table 3, as well as specifications 7-8 in Table 5. The association of age with time preferences remains statistically significant in specifications 1,2 and 5 in Table $3 .^{11}$

\footnotetext{
11 The Bonferroni procedure involves dividing 0.05 by the number of tests $(5)$ and then comparing each calculated $p$ value to the new $p$-value of 0.01 . The Bonferroni-Holm procedure is sequential and compares the rank of each $p$-value to $0.05 /(5-$ rank +1$)$. Both procedures yield qualitatively similar results in our case.
} 


\subsection{Robustness Test with Marshmallow Paradigm}

We also investigate the robustness of our results using the wait time on the marshmallow test as the outcome variable. In Table A.10 in the Appendix, we report on regressions that use the total number of seconds waited as a dependent variable, setting all wait times to 5 minutes for children who waited longer in sessions where it was feasible. We find results that are qualitatively similar to the results that use the time preference variable as an outcome: an increase of 1 year in child age is associated with an increase in wait time of about 6-7 seconds and black children tend to wait 7-27 seconds less than Hispanic children (black children also wait less than white children in some specifications), however, the results are not statistically significant. We also do not find an association of parent time preferences or effects of the Preschool and Parent Academy treatments.

\section{Conclusion}

Time preferences are associated with a range of life outcomes, including educational attainment, health, and financial capability. To shed light on the development of time preferences in children, we conducted experiments to evaluate correlations of child time preferences with age, race, and parental time preferences. We also explored the impact of an early childhood education program on time preferences.

We found that time preferences evolve significantly during ages 3-12, with younger children displaying more impatient preferences than older children. We also found a strong and significant association with race: black children, relative to white or Hispanic children, are significantly more impatient. Parent time preferences are not good predictors of child time preferences, but parents of black children are also more impatient than parents of white or Hispanic children. Interestingly, assignment to different schooling opportunities are not significantly 
associated with our measures of child time preferences. More work is needed to understand the emergence of these observed racial differences, which are present at an early age.

There are certain limitations within our data. First, it is unclear whether the ability to wait is increasing with age because time perceptions change with age (i.e., 1 day to a 3 -year old feels "longer" than 1 day to a 12-year old) or whether the underlying time preference construct is changing. To disentangle these differences, future research should explore how changing the time delay affects willingness to wait by age. Future research should also explore the test-retest reliability of this measure.

Second, it is unclear whether parent preferences are uncorrelated with child preferences, whether the measures that we use are the most appropriate for observing this correlation, or whether the preferences of children are simply difficult to measure. Our results are in line with Bettinger and Slonim (2007) who also found no correlation between adolescent and parent time preferences, but are at odds with Kosse and Pfeiffer (2012; 2013). Notably, we found no association in parent and child time preference using two different measures of time preferences: the standard economic time preference elicitation task, and the delay of gratification paradigm. We also found no association when constraining our sample to mothers only, as Kosse and Pfeiffer $(2012 ; 2013)$ do. An interesting extension would be to systematically use alternative tests of parent preferences, such as a qualitative question with parents, to see if differences in methodology can partly explain the mixed findings in this literature.

Third, because our experiment was not initially designed to disentangle the causal impact of schooling on child time preferences, we only see a sub-set of children in our data who were also part of the CHECC randomization. Hence, while we do not see statistically significant differences in time preferences by treatment assignment, this could be due to a small sample size or due to sample selection. For instance, suppose that random assignment to a CHECC treatment group does 
causally affect child time preferences, but there is differential attendance at the experimental sessions based on child level of impatience, such that parents of more impatient control group children are less likely to attend than parents of more impatient treatment group children. Such a story would undermine our ability to find treatment effects. To address this, we conducted a wave of data collection in 2017-18 that assessed children in school. This allowed us to reach all of the children within one participating district, independent of parental involvement. But this wave occurred several years after the intervention, when the potential effects of the intervention on time preferences could have faded out. We believe that future work should continue to use exogenous variation in early childhood environments to better understand the causal impact of such variation on time preference development.

Finally, another possibility is that early childhood education treatments are causally related to making mistakes in the decision task, which could result in inconsistent decisions. However, when we re-run specification (4) from Tables 5-6 with a 0/1 measure for "consistency" as the dependent variable, we do not observe statistically significant coefficients on CHECC treatment assignment. This is reported as Appendix Table A.11.

Taken together, our results suggest interesting racial disparities in time preferences that emerge from a very young age and appear to persist. A deeper understanding of the determinants of these differences and the extent to which they can be influenced by interventions are important topics for future research. 


\section{References}

Alan, Sule, and Seda Ertac. "Good things come to those who (are taught how to) wait: Results from a randomized educational intervention on time preference." Available at SSRN 2566405 (2014).

Alan, Sule, Nazli Baydar, Teodora Boneva, Seda Ertac, and Thomas F. Crossley. "Parental Socialization Effort and the Intergenerational Transmission of Risk Preferences." (2014).

Almås, Ingvild, Alexander W. Cappelen, Kjell G. Salvanes, Erik Ø. Sørensen, and Bertil Tungodden. "Willingness to compete: Family matters." Management Science 62, no. 8 (2015): 2149-2162.

Andreoni, James, Amalia di Girolamo, John A. List, Claire Maccelvious, and Anya Samek, "Risk Preferences Are Associated with Cognitive Skills and Executive Functions in Children and Adolescents," working paper, 2018.

Andreoni, James, and Charles Sprenger. "Risk preferences are not time preferences." American Economic Review 102.7 (2012): 3357-76.

Andreoni, James and William Harbaugh, "Unexpected Utility and its Alternatives using Convex Risk Budgets," Working paper, 2009.

Angerer, Silvia, Philipp Lergetporer, Daniela Glätzle-Rützler, and Matthias Sutter. "How to measure time preferences in children: a comparison of two methods." Journal of the Economic Science Association 1.2 (2015): 158-169.

Bauer, Michal, Julie Chytilová, and Barbara Pertold-Gebicka. "Parental background and otherregarding preferences in children." Experimental Economics 17.1 (2014): 24-46.

Ben-Ner, Avner, John A. List, Louis Putterman, and Anya Samek. "Learned Generosity? An Artefactual Field Experiment with Parents and Their Children." Journal of Economic Behavior \& Organization 143 (2017): 28-44.

Bettinger, Eric, and Robert Slonim. "Using Experimental Economics to Measure the Effects of a Natural Educational Experiment on Altruism." Journal of Public Economics 90, no. 8-9 (2006): 1625-648.

Bettinger, Eric, and Robert Slonim. "Patience among children." Journal of Public Economics 91.1 (2007): 343-363.

Bradford, David, Charles Courtemanche, Garth Heutel, Patrick Mcalvanah, and Christopher Ruhm. "Time Preferences and Consumer Behavior." Journal of Risk and Uncertainty 55, no. 2-3 (2017): 119-45.

Brown, Heather, and Marjon Van der Pol. "Intergenerational Transfer of Time and Risk Preferences." Journal of Economic Psychology 49 (2015): 187-204.

Busby, Janie, and Thomas Suddendorf. "Recalling Yesterday and Predicting Tomorrow." Cognitive Development 20, no. 3 (2005): 362-72.

Campbell, F.A., C.T. Ramey, E. Pugnello, J. Sparling, and S. Miller-Johnson. "Early childhood education: Young adult outcomes from the Abecedarian Project." Applied developmental science, 6.1 (2002): 42-57.

Cappelen, Alexander W., John A. List, Anya Samek, and Bertil Tungodden. The effect of early education on social preferences. No. w22898. National Bureau of Economic Research, 2016. 
Castillo, Marco, Paul J. Ferraro, Jeffrey L. Jordan, and Ragan Petrie. "The today and tomorrow of kids: Time preferences and educational outcomes of children." Journal of Public Economics 95.11 (2011): 1377-1385.

Castillo, Marco, Jeffrey L. Jordan, and Ragan Petrie. "How much is patience worth? Discount rates of children and high school completion," working paper, 2015.

Castillo, Marco, John A. List, Ragan Petrie, and Anya Samek. "Drivers of Behavior at an Early Age: Evidence from a Large Field Experiment," working paper, 2018.

Chabris, Christopher F., David Laibson, Carrie Morris, Jonathon Schuldt, and Dmitry Taubinsky. "Individual laboratory-measured discount rates predict field behavior." Journal of Risk and Uncertainty 37.2-3 (2008): 237-269.

Chapman, Gretchen B., and Elliot J. Coups. "Time Preferences and Preventive Health Behavior." Medical Decision Making 19, no. 3 (1999): 307-14.

Coller, Maribeth, and Melonie B. Williams. "Eliciting Individual Discount Rates." Experimental Economics 2.2 (1999): 107-127.

Courtemanche, Charles, Garth Heutel, and Patrick McAlvanah. "Impatience, Incentives, and Obesity." The Economic Journal 125, no. 582 (2015): 1-31.

Cowell, Jason M., Anya Samek, John List, and Jean Decety. "The Curious Relation between Theory of Mind and Sharing in Preschool Age Children." Plos One 10, no. 2 (2015).

Cox, James C., John A. List, Michael Price, Vjollca Sadiraj, and Anya Samek. Moral costs and rational choice: Theory and experimental evidence. No. w22234. National Bureau of Economic Research, 2016.

Deckers, Thomas, Armin Falk, Fabian Kosse, and Hannah Schildberg-Hörisch. "How does socioeconomic status shape a child's personality?" (2015).

Eckel, Catherine C., Philip J. Grossman, Cathleen A. Johnson, Angela de Oliveira, Christian Rojas, and Rick K. Wilson. "(Im) patience among Adolescents: A Methodological Note." (2010).

Falk, Armin, and Fabian Kosse. Early childhood environment, breastfeeding and the formation of preferences. No. 2016-036. 2016.

Fryer Jr, Roland G., Steven D. Levitt, and John A. List. Parental incentives and early childhood achievement: a field experiment in Chicago heights. No. w21477. National Bureau of Economic Research, 2015.

Fryer Jr, Roland G., Steven D. Levitt, John A. List, and Anya Samek. "Towards an Understanding of What Works in Preschool Education," working paper, 2018.

Garon, Nancy M., Julie Longard, Susan E. Bryson, and Chris Moore. "Making decisions about now and later: Development of future-oriented self-control." Cognitive Development 27, no. 3 (2012): 314-322.

Golsteyn, Bart HH, Hans Grönqvist, and Lena Lindahl. "Adolescent time preferences predict lifetime outcomes." The Economic Journal 124.580 (2014): F739-F761.

Harrison, Glenn W., John A. List, and Charles Towe. "Naturally occurring preferences and exogenous laboratory experiments: A case study of risk aversion." Econometrica 75, no. 2 (2007): 433-458.

Heckman, James J. "Policies to foster human capital." Research in Economics 54.1 (2000): 3-56. 
Houser, Daniel, John List, Marco Piovesan, Anya Savikhin Samek, and Joachim Winter. "On the Origins of Dishonesty: From Parents to Children." European Economic Review 82 (2015): 242-54.

Karniol, Rachel, Lior Galili, Dafna Shtilerman, Reut Naim, Karin Stern, Hadar Manjoch, and Rotem Silverman. "Why superman can wait: Cognitive self-transformation in the delay of gratification paradigm." Journal of Clinical Child \& Adolescent Psychology 40.2 (2011): 307-317.

Khwaja, Ahmed, Frank Sloan, and Martin Salm. "Evidence on Preferences and Subjective Beliefs of Risk Takers: The Case of Smokers." International Journal of Industrial Organization 24, no. 4 (2006): 667-82.

Kosse, Fabian, and Friedhelm Pfeiffer. "Impatience among preschool children and their mothers." Economics Letters 115.3 (2012): 493-495.

Kosse, Fabian, and Friedhelm Pfeiffer. "Quasi-hyperbolic time preferences and their intergenerational transmission.” Applied Economics Letters, 20.10 (2013): 983-986.

Lemmon, Karen, and Chris Moore. "The development of prudence in the face of varying future rewards." Developmental Science 10.4 (2007): 502-511.

List, John A., and Anya C. Samak. "Exploring the Origins of Charitable Acts: Evidence from an Artefactual Field Experiment with Young Children." Economics Letters 118, no. 3 (2013): 431-34.

List, John A., Azeem M. Shaikh, and Yang Xu. Multiple hypothesis testing in experimental economics. No. w21875. National Bureau of Economic Research, 2016.

List, John A., Anya Samek, and Dana L. Suskind. "Combining Behavioral Economics and Field Experiments to Reimagine Early Childhood Education." Behavioural Public Policy 2, no. 01 (2018): 1-21.

Lührmann, Melanie, Marta Serra-Garcia, and Joachim K. Winter. "The impact of financial education on adolescents' intertemporal choices." (2014).

Meier, Stephan, and Charles D. Sprenger. "Discounting Financial Literacy: Time Preferences and Participation in Financial Education Programs." Journal of Economic Behavior \& Organization 95 (2013): 159-74.

Mischel, Walter, Yuichi Shoda, and Monica L. Rodriguez. "Delay of gratification in children." Science 244.4907 (1989): 933-938.

Mischel, Walter, Ebbe B. Ebbesen, and Antonette Raskoff Zeiss. "Cognitive and Attentional Mechanisms in Delay of Gratification." Journal of Personality and Social Psychology 21, no. 2 (1972): 204-18.

Mischel, Walter, and Bert Moore. "Effects of Attention to Symbolically Presented Rewards on Self-control." Journal of Personality and Social Psychology 28, no. 2 (1973): 172-79.

Oswald, Yvonne, and Uschi Backes-Gellner. "Learning for a Bonus: How Financial Incentives Interact with Preferences." Journal of Public Economics 118 (2014): 52-61.

Picone, Gabriel, Frank Sloan, and Jr. Donald Taylor. "Effects of Risk and Time Preference and Expected Longevity on Demand for Medical Tests." Journal of Risk and Uncertainty 28, no. 1 (2004): 39-53.

Sadoff, Sally, and Anya Samek. "Can Interventions Affect Commitment Demand? A Field Experiment on Food Choice." Journal of Economic Behavior \& Organization, 2018. 
Samak, Anya C. "Is There a Gender Gap in Preschoolers' Competitiveness? An Experiment in the U.S." Journal of Economic Behavior \& Organization 92 (2013): 22-31.

Samek, Anya, and Roman M. Sheremeta. "Selective Recognition: How To Recognize Donors To Increase Charitable Giving." Economic Inquiry 55, no. 3 (2017): 1489-496.

Schildberg-Hörisch, Hannah, Thomas Deckers, Armin Falk, and Fabian Kosse. "How Does SocioEconomic Status Shape a Child's Personality?" (2014).

Schwarz, J. Conrad, Janet B. Schrager, and Andrea E. Lyons. "Delay of gratification by preschoolers: Evidence for the validity of the choice paradigm." Child Development (1983): 620-625.

Schweinhart, Lawrence J. Significant Benefits: The High/Scope Perry Preschool Study through Age 27. Monographs of the High/Scope Educational Research Foundation, No. Ten. High/Scope Educational Research Foundation, 600 North River Street, Ypsilanti, MI 48198-2898 (1993).

Shoda, Yuichi, Walter Mischel, and Philip K. Peake. "Predicting Adolescent Cognitive and Selfregulatory Competencies from Preschool Delay of Gratification: Identifying Diagnostic Conditions." Developmental Psychology 26, no. 6 (1990): 978-86.

Sutter, Matthias, Martin G. Kocher, Daniela Glätzle-Rützler, and Stefan T. Trautmann. "Impatience and Uncertainty: Experimental Decisions Predict Adolescents Field Behavior." American Economic Review 103, no. 1 (2013): 510-31.

Sutter, Matthias, Levent Yilmaz, and Manuela Oberauer. "Delay of Gratification and the Role of Defaults-An Experiment with Kindergarten Children." Economics Letters 137 (2015): 21-24.

Webley, Paul, and Ellen K. Nyhus. "Parents' influence on children's future orientation and saving." Journal of Economic Psychology 27.1 (2006): 140-164.

Weller, Rosalyn E., Edwin W. Cook, Kathy B. Avsar, and James E. Cox. "Obese Women Show Greater Delay Discounting than Healthy-weight Women." Appetite 51, no. 3 (2008): 56369.

Wilhelm, Mark Ottoni, Eleanor Brown, Patrick M. Rooney, and Richard Steinberg. "The intergenerational transmission of generosity." Journal of Public Economics 92, no. 10 (2008): 2146-2156.

Willoughby, Michael T., Laura J. Kuhn, Clancy B. Blair, Anya Samek, and John A. List. "The Test-retest Reliability of the Latent Construct of Executive Function Depends on Whether Tasks Are Represented as Formative or Reflective Indicators." Child Neuropsychology 23, no. 7 (2017): 822-837. 
Table 1: Child Experiment Design

\begin{tabular}{llll}
\hline Wave & \multicolumn{2}{l}{$\begin{array}{l}\text { Elicitation task } \\
\text { (today vs tomorrow) }\end{array}$} & Incentives \\
\hline $2010-11$ & $4 \mathrm{v} 5,4 \mathrm{v} 6,4 \mathrm{v} 7,4 \mathrm{v} 8$ & Candies & One-on-one or in a group \\
2012 & $3 \mathrm{v} 3,2 \mathrm{v} 3,1 \mathrm{v} 3$ & Candies & Outside of school \\
2013 & $2 \mathrm{v} 3,2 \mathrm{v} 4,2 \mathrm{v} 5,2 \mathrm{v} 6$ & Candies & One-on-one, outside of school \\
$2017-18$ & $4 \mathrm{v} 5,4 \mathrm{v} 6,4 \mathrm{v} 7,4 \mathrm{v} 8$ & Choice of Candies/Prizes & One-on-one, in-school \\
& $($ same as 2010-11) & \\
\hline
\end{tabular}

Note: The table reports the experiment design for the child experiments, broken down by wave. 
Table 2: Summary of Observations

\begin{tabular}{lccccc}
\hline \hline & Wave 2010-11 & Wave 2012 & Wave 2013 & Wave 2017-18 & Total \\
\hline Child Age Range (Years): & $3-12$ & $4-8$ & $3-6$ & $6-12$ & $3-12$ \\
Child Age (in Years) & 5.60 & 5.24 & 4.73 & 9.76 & 6.93 \\
& $(0.14)$ & $(0.05)$ & $(0.04)$ & $(0.05)$ & $(0.07)$ \\
Child Gender (Female=1) & 0.48 & 0.48 & 0.54 & 0.49 & 0.50 \\
Child Race - Black & 0.37 & 0.51 & 0.41 & 0.23 & 0.35 \\
Child Race - Hispanic & 0.49 & 0.37 & 0.49 & 0.72 & 0.56 \\
Child Race - Other & 0.01 & 0.01 & 0.01 & 0.00 & 0.01 \\
Child Race - White & 0.13 & 0.11 & 0.09 & 0.04 & 0.08 \\
Household Income (0-15k) & 0.21 & 0.31 & 0.28 & 0.32 & 0.29 \\
Household Income (16k-35k) & 0.20 & 0.26 & 0.34 & 0.27 & 0.28 \\
Household Income (36k-60k) & 0.13 & 0.13 & 0.11 & 0.09 & 0.11 \\
Household Income (60k+) & 0.06 & 0.08 & 0.10 & 0.02 & 0.06 \\
Mother Edu (Less than High School) & 0.12 & 0.11 & 0.15 & 0.23 & 0.17 \\
Mother Edu (High School) & 0.31 & 0.40 & 0.35 & 0.35 & 0.35 \\
Mother Edu (College) & 0.20 & 0.33 & 0.31 & 0.13 & 0.23 \\
Cog Pre-Assess. & 0.37 & 0.39 & 0.37 & 0.29 & 0.34 \\
& $(0.01)$ & $(0.01)$ & $(0.01)$ & $(0.01)$ & $(0.01)$ \\
Non-Cog Pre-Assess. & 0.66 & 0.58 & 0.51 & 0.50 & 0.55 \\
Pretest Cog Missing & $(0.01)$ & $(0.01)$ & $(0.01)$ & $(0.01)$ & $(0.01)$ \\
Pretest EF Missing & 0.04 & 0.13 & 0.09 & 0.20 & 0.13 \\
Cog Missing & 0.04 & 0.13 & 0.11 & 0.22 & 0.14 \\
EF Missing & 0.30 & 0.43 & 0.55 & 0.01 & 0.28 \\
Income Missing & 0.30 & 0.43 & 0.55 & 0.03 & 0.29 \\
Mother Educ Missing & 0.40 & 0.22 & 0.18 & 0.30 & 0.27 \\
Observations & 0.38 & 0.16 & 0.18 & 0.28 & 0.25 \\
\hline \hline
\end{tabular}

Note: The table reports sample averages. Standard errors are in parentheses. The number of observations is the number of subjects in each wave, regardless of if they participated in the previous wave. Total observations represents total number of assessments conducted, rather than total number of children. Demographic data is available for nearly all observations. Age is available for all observations. Gender is available for all but 7 observations ( 6 children), and race is available for all but 15 observations (15 children). SES data is only available for children whose parents completed the voluntary questionnaire. 


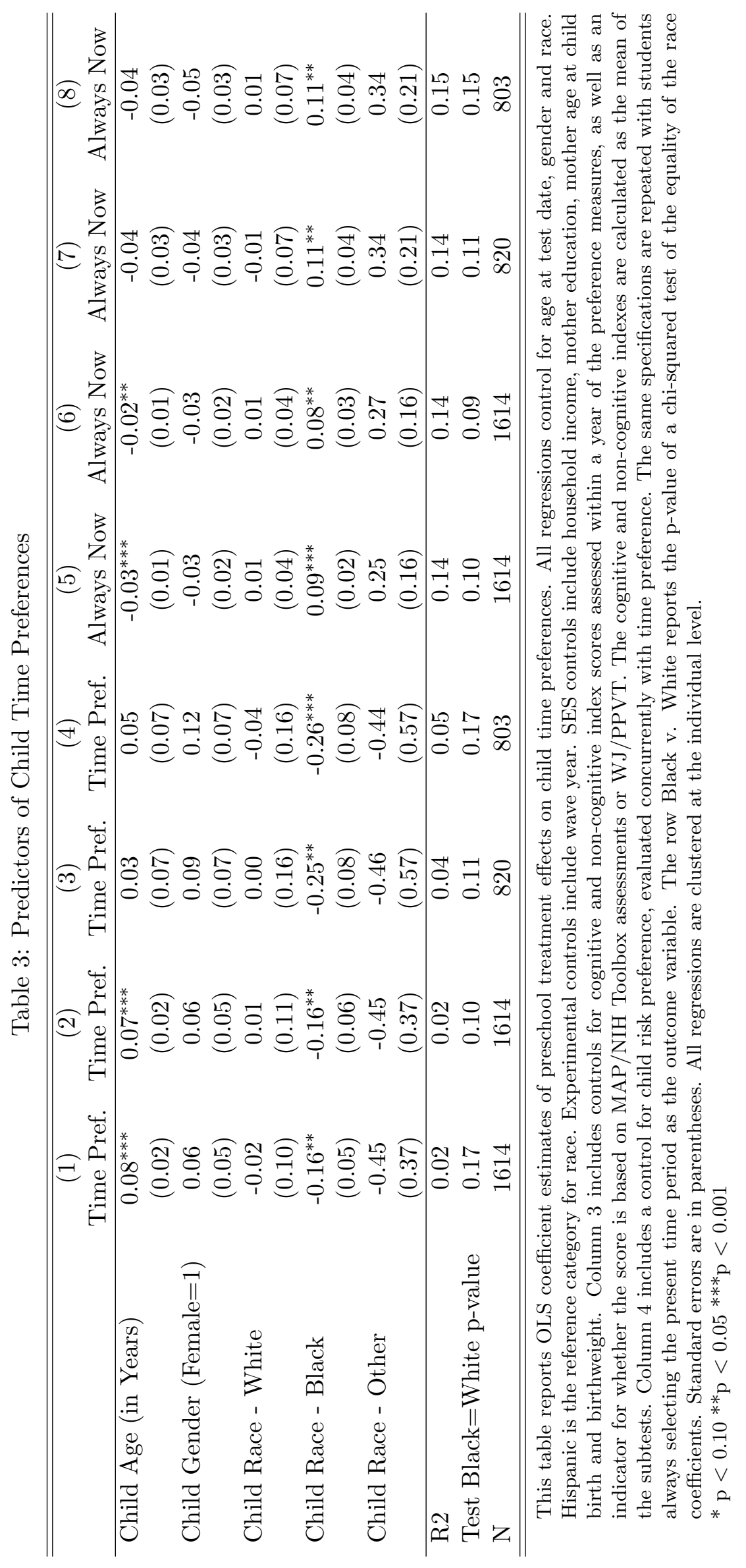




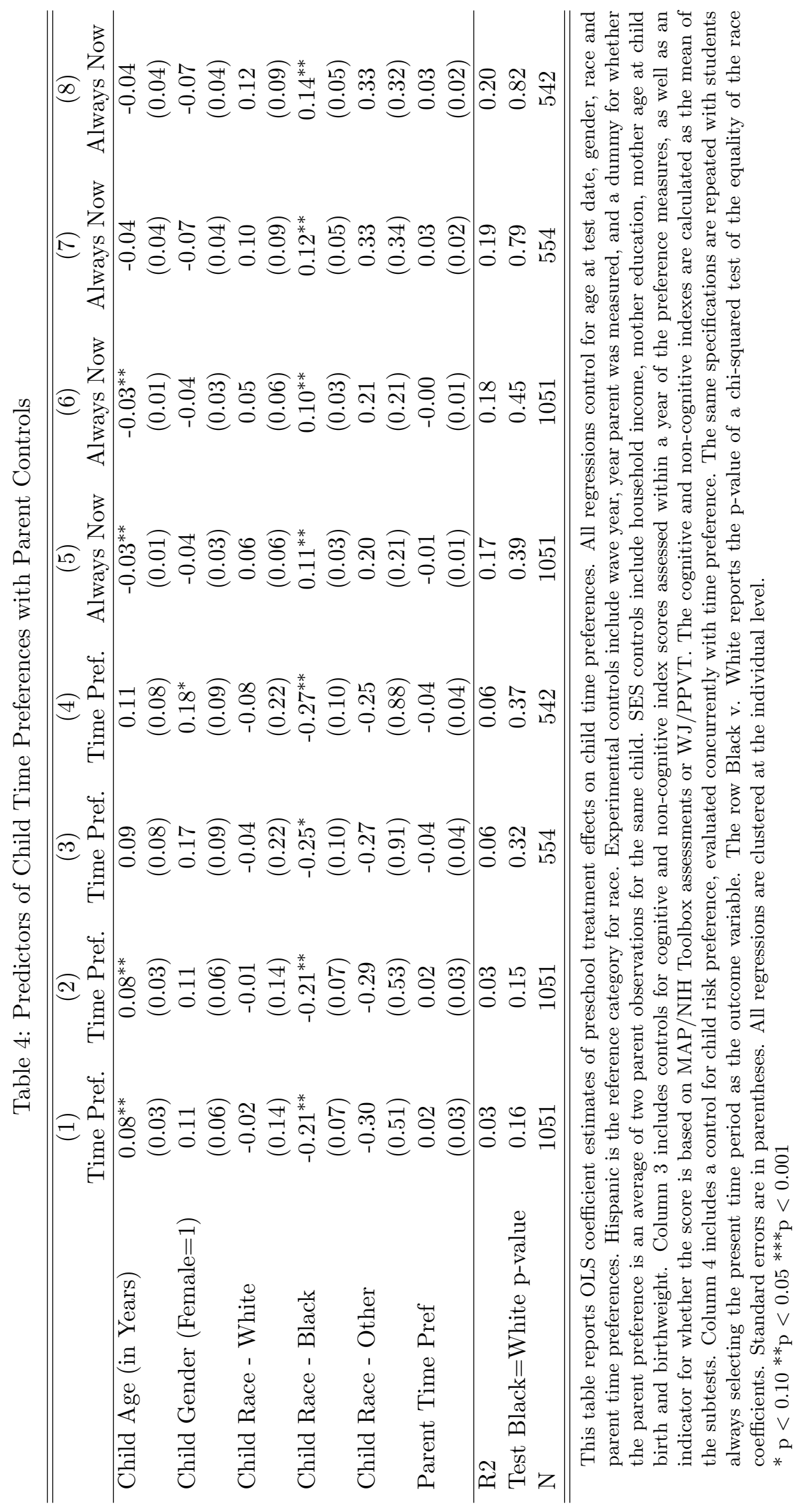




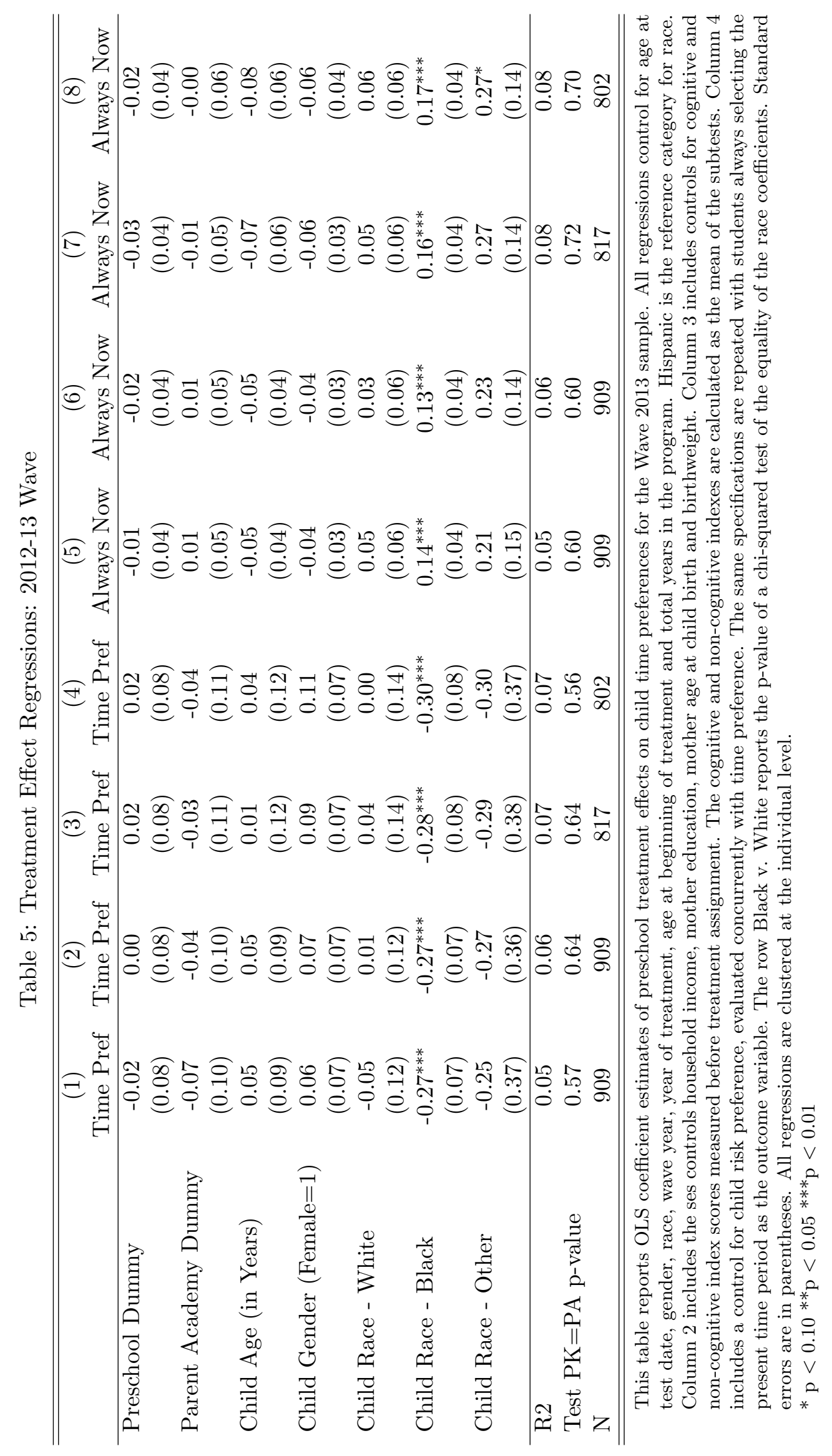




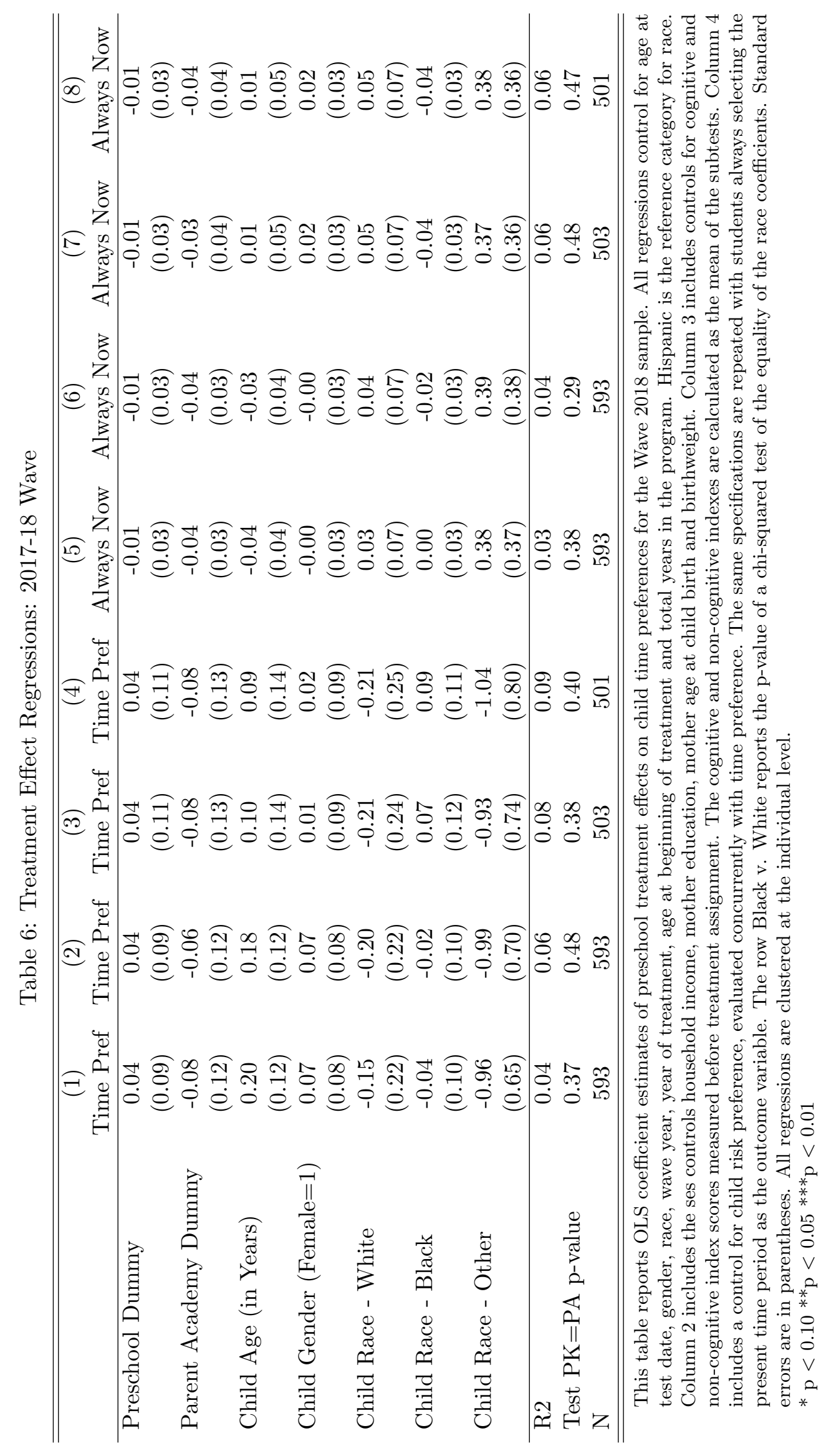




\section{Figures}

Figure 1: Histogram of Child Decisions
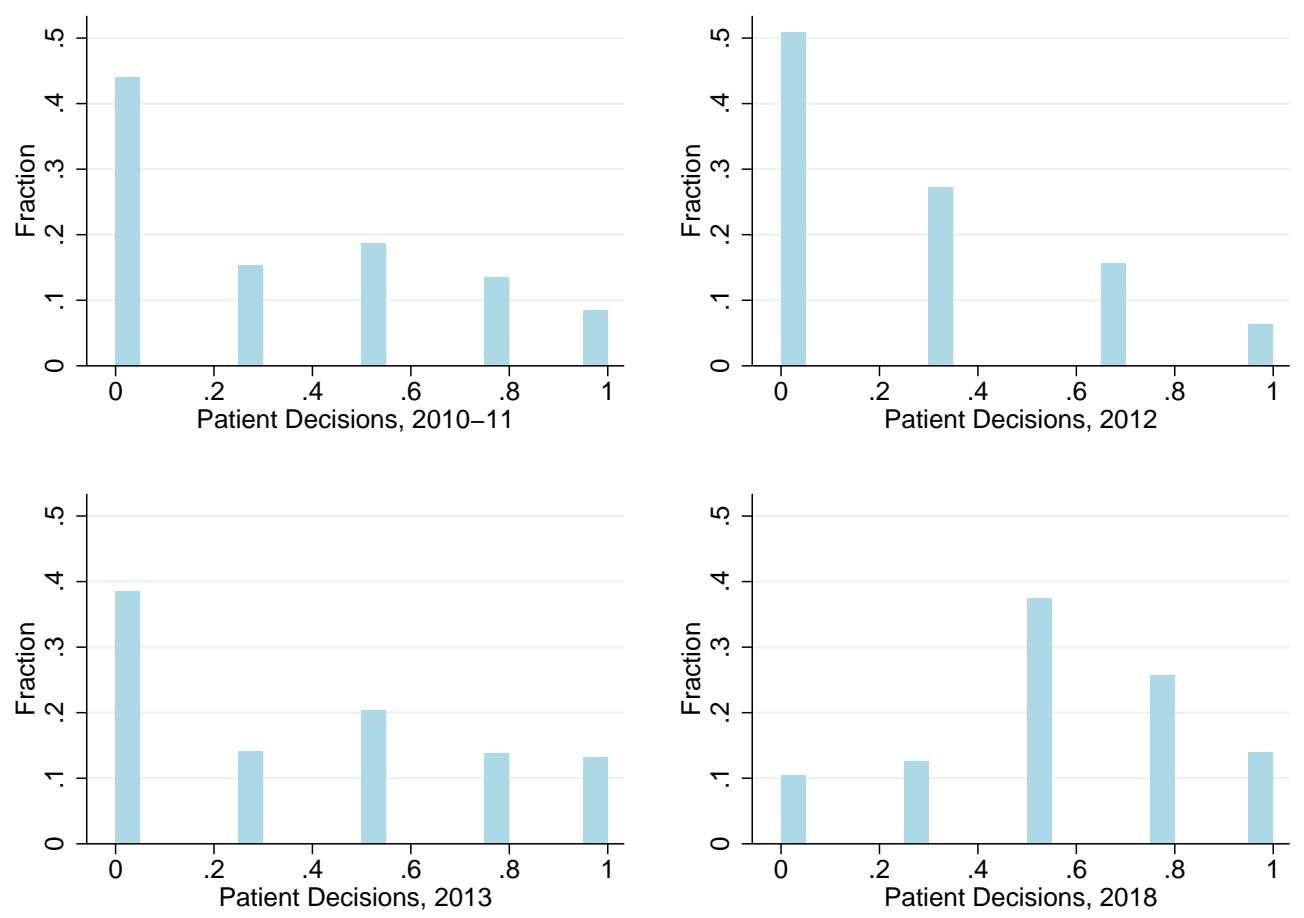

Figure 2: Proportion Child Patient by Decision and Wave

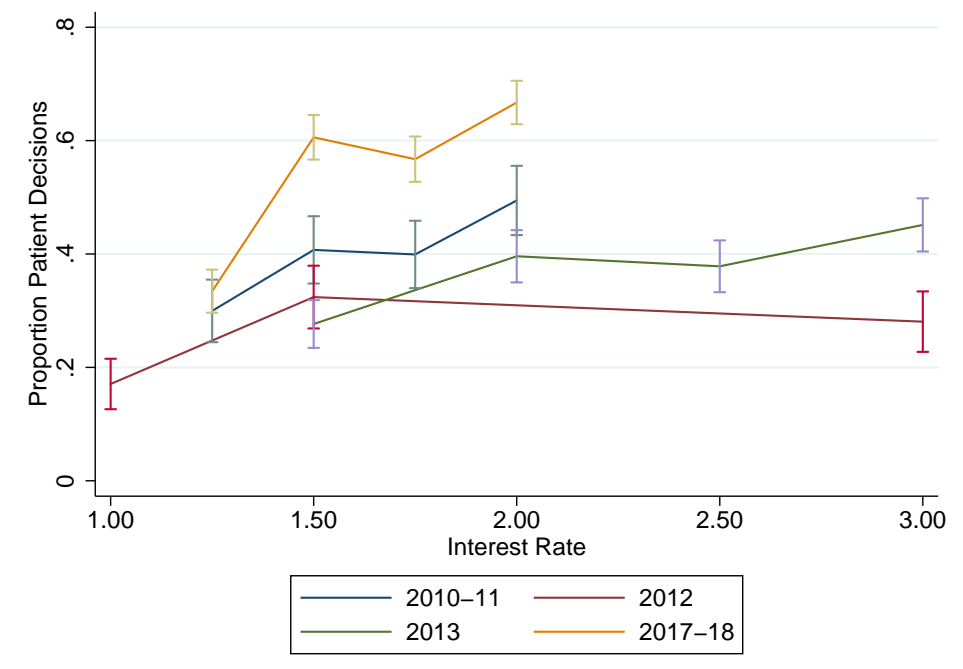


Figure 3: Histogram of Child Ages by Wave

Wave, 2010

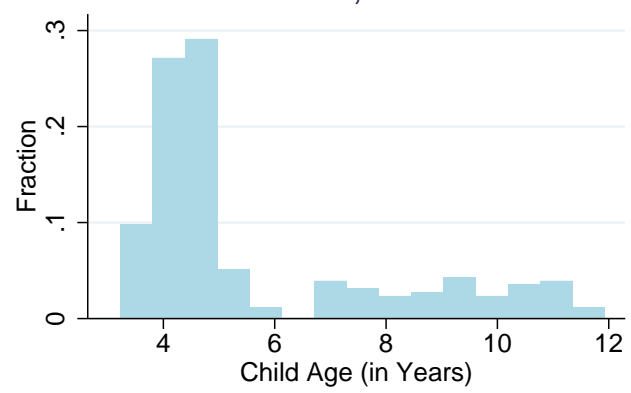

Wave, 2013

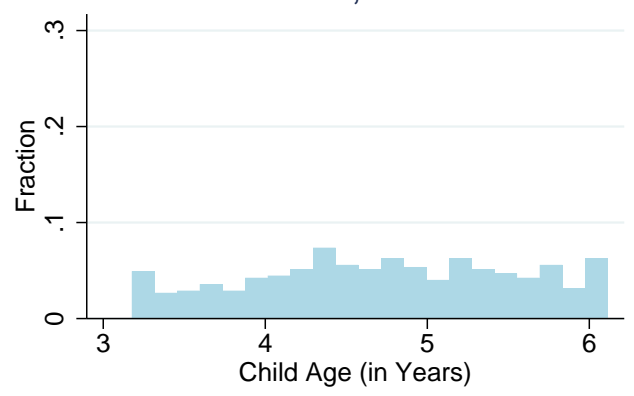

Wave, 2012

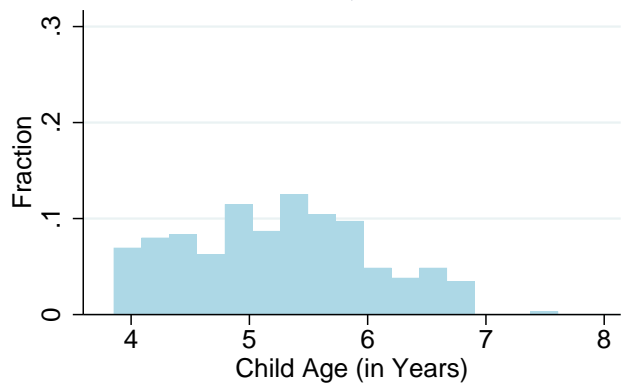

Wave, 2018

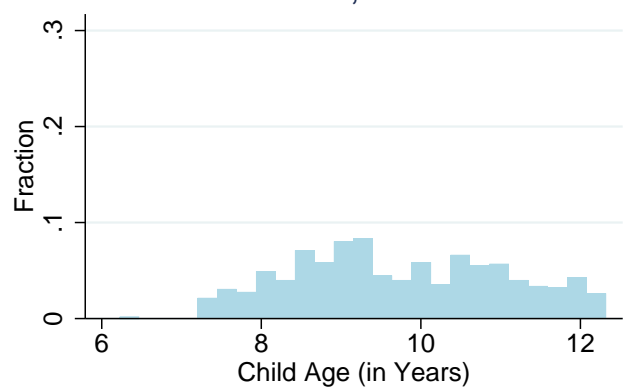

Figure 4: Patient and Monotonic Decisions, by age

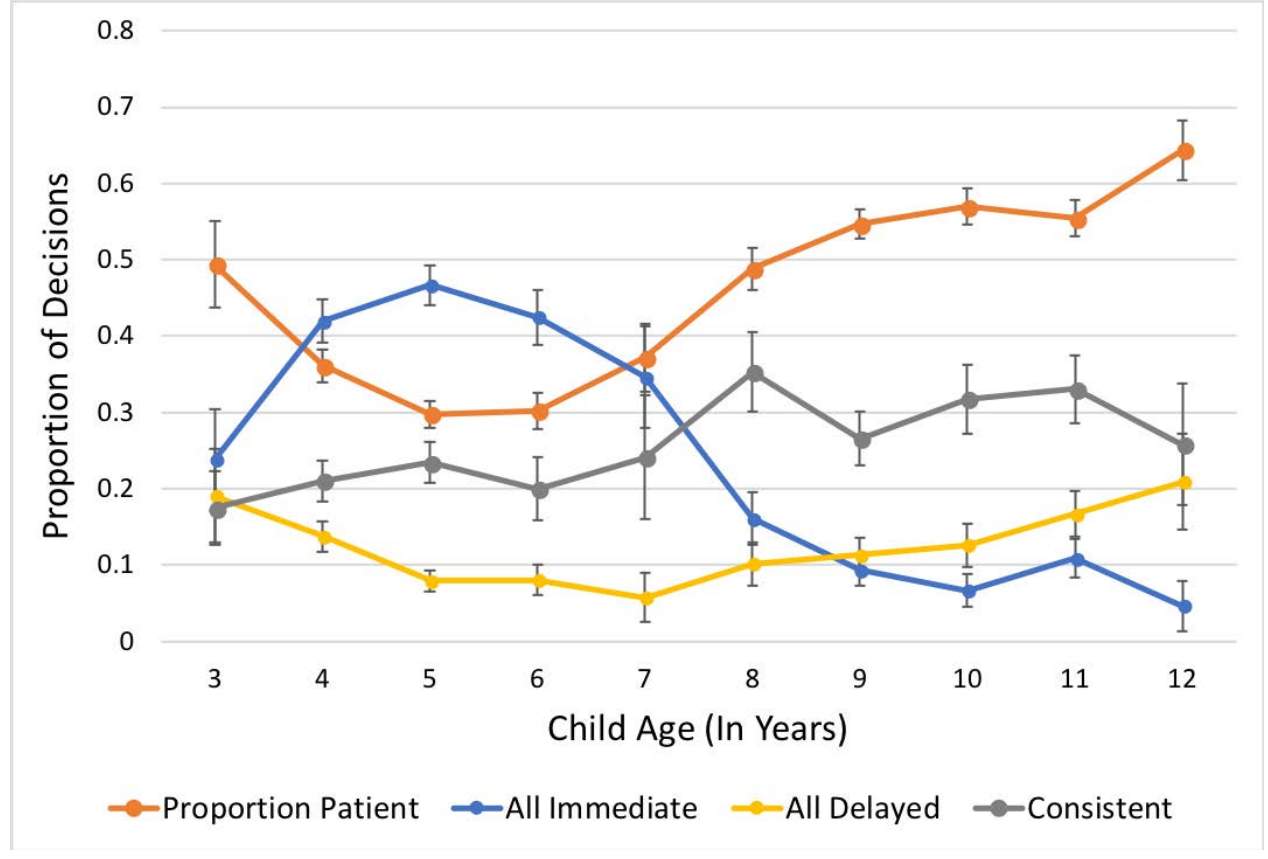


A Appendix Tables and Figures

Table A.1: Child Time Preferences with Quadratic Age

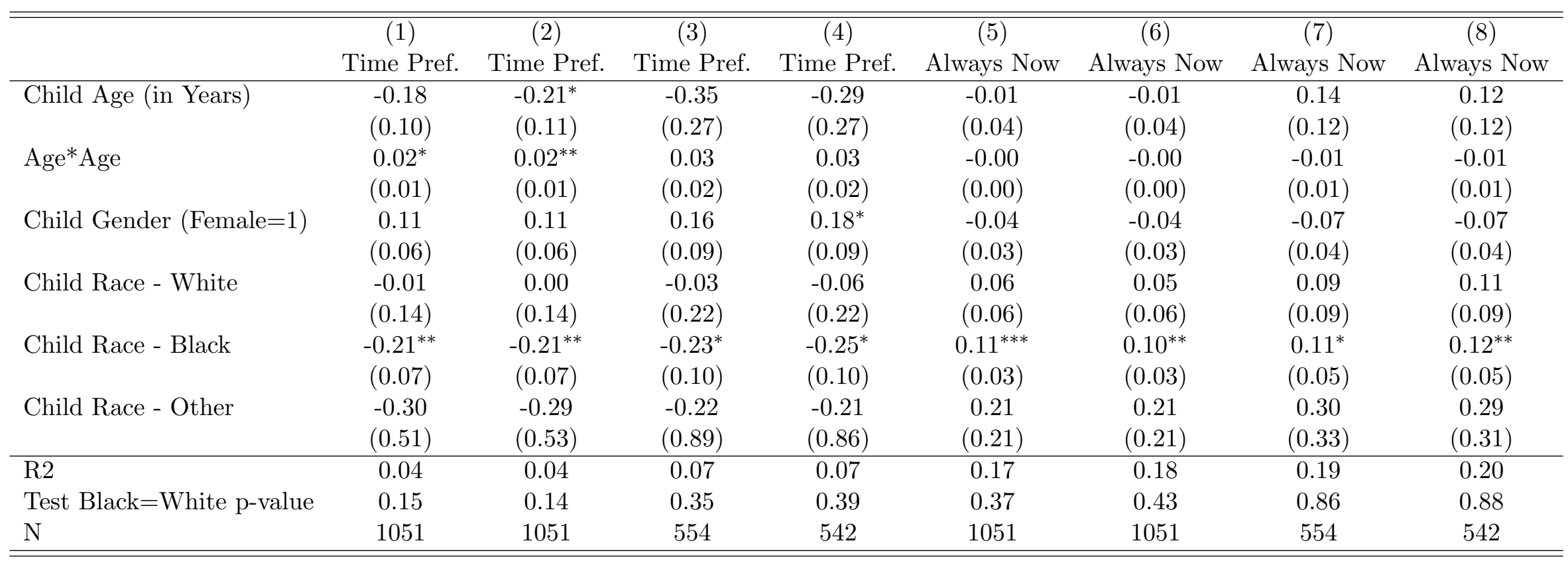

This table reports OLS coefficient estimates of preschool treatment effects on child time preferences. All regressions control for age at test date, age squared at test date, gender and race. Hispanic is the reference category for race. Experimental controls include wave year. SES controls include household income, mother education, mother age at child birth and birthweight. Column 3 includes controls for cognitive and non-cognitive index scores assessed within a year of the preference measures, as well as an indicator for whether the score is based on MAP/NIH Toolbox assessments or WJ/PPVT. The cognitive and non-cognitive indexes are calculated as the mean of the subtests. Column 4 includes a control for child risk preference, evaluated concurrently with time preference. The same specifications are repeated with students always selecting the present time period as the outcome variable. The row Black v. White reports the p-value of a chi-squared test of the equality of the race coefficients. Standard errors are in parentheses. All regressions are clustered at the individual level.

$* \mathrm{p}<0.10 * * \mathrm{p}<0.05^{* * *} \mathrm{p}<0.001$ 
Table A.2: Child Time Preferences with Race Age Interaction

\begin{tabular}{|c|c|c|c|c|c|c|c|c|}
\hline & $\begin{array}{c}(1) \\
\text { Time Pref. }\end{array}$ & $\begin{array}{c}(2) \\
\text { Time Pref. }\end{array}$ & $\begin{array}{c}(3) \\
\text { Time Pref. }\end{array}$ & $\begin{array}{c}(4) \\
\text { Time Pref. }\end{array}$ & $\begin{array}{c}(5) \\
\text { Always Now }\end{array}$ & $\begin{array}{c}(6) \\
\text { Always Now }\end{array}$ & $\begin{array}{c}(7) \\
\text { Always Now }\end{array}$ & $\begin{array}{c}(8) \\
\text { Always Now }\end{array}$ \\
\hline Child Age (in Years) & $\begin{array}{c}0.06^{*} \\
(0.03)\end{array}$ & $\begin{array}{c}0.05 \\
(0.03)\end{array}$ & $\begin{array}{c}0.08 \\
(0.08)\end{array}$ & $\begin{array}{c}0.09 \\
(0.08)\end{array}$ & $\begin{array}{c}-0.02 \\
(0.01)\end{array}$ & $\begin{array}{l}-0.02 \\
(0.01)\end{array}$ & $\begin{array}{l}-0.03 \\
(0.04)\end{array}$ & $\begin{array}{l}-0.04 \\
(0.04)\end{array}$ \\
\hline Child Gender (Female $=1$ ) & $\begin{array}{c}0.10 \\
(0.06)\end{array}$ & $\begin{array}{c}0.11 \\
(0.06)\end{array}$ & $\begin{array}{c}0.16 \\
(0.09)\end{array}$ & $\begin{array}{l}0.18^{*} \\
(0.09)\end{array}$ & $\begin{array}{l}-0.04 \\
(0.03)\end{array}$ & $\begin{array}{l}-0.04 \\
(0.03)\end{array}$ & $\begin{array}{l}-0.06 \\
(0.04)\end{array}$ & $\begin{array}{l}-0.07 \\
(0.04)\end{array}$ \\
\hline Child Race - White & $\begin{array}{c}-0.33 \\
(0.33)\end{array}$ & $\begin{array}{l}-0.32 \\
(0.33)\end{array}$ & $\begin{array}{c}0.46 \\
(0.87)\end{array}$ & $\begin{array}{c}0.36 \\
(0.89)\end{array}$ & $\begin{array}{c}0.33^{*} \\
(0.14)\end{array}$ & $\begin{array}{c}0.33^{*} \\
(0.14)\end{array}$ & $\begin{array}{c}0.00 \\
(0.34)\end{array}$ & $\begin{array}{c}0.07 \\
(0.33)\end{array}$ \\
\hline Child Race - Black & $\begin{array}{c}-0.62^{* *} \\
(0.20)\end{array}$ & $\begin{array}{c}-0.64^{* *} \\
(0.20)\end{array}$ & $\begin{array}{l}-0.74^{*} \\
(0.32)\end{array}$ & $\begin{array}{l}-0.77^{*} \\
(0.33)\end{array}$ & $\begin{array}{c}0.34^{* * *} \\
(0.09)\end{array}$ & $\begin{array}{c}0.34^{* * *} \\
(0.09)\end{array}$ & $\begin{array}{l}0.35^{*} \\
(0.14)\end{array}$ & $\begin{array}{l}0.38^{*} \\
(0.15)\end{array}$ \\
\hline Child Race - Other & $\begin{array}{c}1.35 \\
(0.94)\end{array}$ & $\begin{array}{c}1.36 \\
(0.96)\end{array}$ & $\begin{array}{c}1.86 \\
(1.53)\end{array}$ & $\begin{array}{c}1.87 \\
(1.49)\end{array}$ & $\begin{array}{l}-0.42 \\
(0.44)\end{array}$ & $\begin{array}{l}-0.37 \\
(0.42)\end{array}$ & $\begin{array}{l}-0.27 \\
(0.54)\end{array}$ & $\begin{array}{l}-0.24 \\
(0.52)\end{array}$ \\
\hline White* Age & $\begin{array}{c}0.04 \\
(0.04)\end{array}$ & $\begin{array}{c}0.04 \\
(0.04)\end{array}$ & $\begin{array}{l}-0.09 \\
(0.16)\end{array}$ & $\begin{array}{l}-0.08 \\
(0.16)\end{array}$ & $\begin{array}{c}-0.04^{* *} \\
(0.01)\end{array}$ & $\begin{array}{c}-0.04^{* *} \\
(0.02)\end{array}$ & $\begin{array}{c}0.02 \\
(0.06)\end{array}$ & $\begin{array}{c}0.01 \\
(0.06)\end{array}$ \\
\hline Black*Age & $\begin{array}{l}0.06^{*} \\
(0.03)\end{array}$ & $\begin{array}{l}0.06^{*} \\
(0.03)\end{array}$ & $\begin{array}{c}0.08 \\
(0.05)\end{array}$ & $\begin{array}{c}0.08 \\
(0.05)\end{array}$ & $\begin{array}{c}-0.03^{* *} \\
(0.01)\end{array}$ & $\begin{array}{c}-0.03^{* *} \\
(0.01)\end{array}$ & $\begin{array}{l}-0.04 \\
(0.02)\end{array}$ & $\begin{array}{l}-0.04 \\
(0.02)\end{array}$ \\
\hline Other*Age & $\begin{array}{c}-0.31^{* *} \\
(0.12)\end{array}$ & $\begin{array}{c}-0.31^{*} \\
(0.12)\end{array}$ & $\begin{array}{c}-0.37^{*} \\
(0.16)\end{array}$ & $\begin{array}{c}-0.37^{*} \\
(0.16)\end{array}$ & $\begin{array}{c}0.12 \\
(0.07)\end{array}$ & $\begin{array}{c}0.11 \\
(0.07)\end{array}$ & $\begin{array}{c}0.10 \\
(0.07)\end{array}$ & $\begin{array}{c}0.09 \\
(0.07)\end{array}$ \\
\hline $\mathrm{R} 2$ & 0.04 & 0.04 & 0.07 & 0.07 & 0.18 & 0.19 & 0.19 & 0.20 \\
\hline Test Black=White $p$-value & 0.39 & 0.37 & 0.18 & 0.21 & 0.97 & 0.99 & 0.32 & 0.38 \\
\hline $\mathrm{N}$ & 1051 & 1051 & 554 & 542 & 1051 & 1051 & 554 & 542 \\
\hline
\end{tabular}

This table reports OLS coefficient estimates of preschool treatment effects on child time preferences, with race-age interaction terms. All regressions control for age at test date, gender, race and age-race interactions. Hispanic is the reference category for race. Experimental controls include wave year. SES controls include household income, mother education, mother age at child birth and birthweight. Column 3 includes controls for cognitive and non-cognitive index scores assessed within a year of the preference measures, as well as an indicator for whether the score is based on MAP/NIH Toolbox assessments or WJ/PPVT. The cognitive and non-cognitive indexes are calculated as the mean of the subtests. Column 4 includes a control for child risk preference, evaluated concurrently with time preference. The same specifications are repeated with students always selecting the present time period as the outcome variable. The row Black v. White reports the p-value of a chi-squared test of the equality of the race coefficients. Standard errors are in parentheses. All regressions are clustered at the individual level.

$* \mathrm{p}<0.10 * * \mathrm{p}<0.05^{* * *} \mathrm{p}<0.001$ 
Table A.3: Mothers Only

\begin{tabular}{|c|c|c|c|c|c|c|c|c|}
\hline & $\begin{array}{c}\text { (1) } \\
\text { Time Pref. }\end{array}$ & $\begin{array}{c}(2) \\
\text { Time Pref. }\end{array}$ & $\begin{array}{c}(3) \\
\text { Time Pref. }\end{array}$ & $\begin{array}{c}(4) \\
\text { Time Pref. }\end{array}$ & $\begin{array}{c}(5) \\
\text { Always Now }\end{array}$ & $\begin{array}{c}(6) \\
\text { Always Now }\end{array}$ & $\begin{array}{c}(7) \\
\text { Always Now }\end{array}$ & $\begin{array}{c}(8) \\
\text { Always Now }\end{array}$ \\
\hline \multirow[t]{2}{*}{ Child Age (in Years) } & $0.07^{*}$ & 0.06 & 0.04 & 0.06 & $-0.03^{* *}$ & $-0.03^{* *}$ & -0.03 & $-0.04^{*}$ \\
\hline & $(0.03)$ & $(0.03)$ & $(0.04)$ & $(0.04)$ & $(0.01)$ & $(0.01)$ & $(0.02)$ & $(0.02)$ \\
\hline \multirow[t]{2}{*}{ Child Gender $($ Female $=1)$} & 0.12 & 0.12 & 0.13 & $0.15^{*}$ & -0.06 & -0.06 & -0.05 & -0.05 \\
\hline & $(0.07)$ & $(0.07)$ & $(0.08)$ & $(0.08)$ & $(0.03)$ & $(0.03)$ & $(0.03)$ & $(0.03)$ \\
\hline \multirow[t]{2}{*}{ Child Race - White } & -0.06 & -0.07 & -0.07 & -0.09 & 0.06 & 0.07 & 0.07 & 0.08 \\
\hline & $(0.14)$ & $(0.15)$ & $(0.15)$ & $(0.15)$ & $(0.06)$ & $(0.06)$ & $(0.06)$ & $(0.06)$ \\
\hline \multirow[t]{2}{*}{ Child Race - Black } & $-0.22^{* *}$ & $-0.21^{*}$ & $-0.18^{*}$ & $-0.20^{*}$ & $0.11^{* *}$ & $0.09^{*}$ & $0.10^{*}$ & $0.11^{* *}$ \\
\hline & $(0.08)$ & $(0.08)$ & $(0.08)$ & $(0.09)$ & $(0.04)$ & $(0.04)$ & $(0.04)$ & $(0.04)$ \\
\hline \multirow[t]{2}{*}{ Child Race - Other } & -0.24 & -0.24 & -0.25 & -0.22 & 0.17 & 0.18 & 0.18 & 0.18 \\
\hline & $(0.54)$ & $(0.55)$ & $(0.57)$ & $(0.56)$ & $(0.22)$ & $(0.22)$ & $(0.22)$ & $(0.21)$ \\
\hline \multirow[t]{2}{*}{ Mother's Time Pref. } & 0.02 & 0.02 & 0.00 & 0.01 & -0.01 & -0.01 & -0.00 & -0.00 \\
\hline & $(0.04)$ & $(0.04)$ & $(0.04)$ & $(0.04)$ & $(0.02)$ & $(0.02)$ & $(0.02)$ & $(0.02)$ \\
\hline $\mathrm{R} 2$ & 0.02 & 0.03 & 0.04 & 0.04 & 0.18 & 0.19 & 0.20 & 0.21 \\
\hline Test Black $=$ White $p$-value & 0.29 & 0.36 & 0.45 & 0.48 & 0.44 & 0.70 & 0.70 & 0.71 \\
\hline $\mathrm{N}$ & 766 & 766 & 737 & 724 & 766 & 766 & 737 & 724 \\
\hline
\end{tabular}

This table reports OLS coefficient estimates of preschool treatment effects on child time preferences. All regressions control for age at test date, gender, race and parent time preferences if the parent was the mother. Hispanic is the reference category for race. Experimental controls include year of treatment and year mom was measured. SES controls include household income, mother education, mother age at child birth and birthweight. Column 3 includes controls for cognitive and non-cognitive index scores assessed within a year of the preference measures, as well as an indicator for whether the score is based on MAP/NIH Toolbox assessments or WJ/PPVT. The cognitive and non-cognitive indexes are calculated as the mean of the subtests. Column 4 includes a control for child risk preference, evaluated concurrently with time preference. The same specifications are repeated with students always selecting the present time period as the outcome variable. The row Black v. White reports the p-value of a chi-squared test of the equality of the race coefficients. Standard errors are in parentheses.

$* \mathrm{p}<0.10^{* *} \mathrm{p}<0.05 * * * \mathrm{p}<0.001$ 
Table A.4: Parent Correlations

\begin{tabular}{lcccc}
\hline \hline & $(1)$ & $(2)$ & $(3)$ & $(4)$ \\
& Time Pref & Time Pref & Always Now & Always Now \\
\hline Female & 0.17 & 0.19 & -0.03 & -0.03 \\
& $(0.11)$ & $(0.11)$ & $(0.03)$ & $(0.03)$ \\
White & 0.04 & -0.02 & -0.03 & -0.02 \\
& $(0.15)$ & $(0.16)$ & $(0.03)$ & $(0.03)$ \\
Black & $-0.38^{* * *}$ & $-0.40^{* * *}$ & $0.07^{* *}$ & $0.08^{* *}$ \\
& $(0.09)$ & $(0.09)$ & $(0.02)$ & $(0.03)$ \\
Other & -0.17 & -0.36 & $-0.06^{* * *}$ & -0.02 \\
& $(0.45)$ & $(0.43)$ & $(0.01)$ & $(0.03)$ \\
Multiple Race & $-0.42^{*}$ & $-0.41^{*}$ & 0.07 & 0.06 \\
& $(0.20)$ & $(0.20)$ & $(0.07)$ & $(0.07)$ \\
Constant & 0.01 & 0.02 & $0.09^{* *}$ & $0.09^{*}$ \\
& $(0.11)$ & $(0.15)$ & $(0.03)$ & $(0.04)$ \\
\hline R2 & 0.04 & 0.06 & 0.03 & 0.04 \\
Test Black=White p-value & 0.01 & 0.02 & 0.00 & 0.00 \\
$\mathrm{~N}$ & 632 & 632 & 632 & 632 \\
\hline \hline
\end{tabular}

This table reports OLS coefficient estimates of treatment effects on parent time preferences. All regressions control for age at test date, gender and child's race. Hispanic is the reference category for race. Experimental controls include year of treatment, year parent was measured, and a dummy for whether the parent preference is an average of two parent observations for the same child. SES controls include household income, mother education, mother age at child birth and birthweight. The same specifications are repeated with parents always selecting the present time period as the outcome variable. The row Black $\mathrm{v}$. White reports the p-value of a chi-squared test of the equality of the race coefficients. Standard errors are in parentheses.

${ }^{*} \mathrm{p}<0.10{ }^{* *} \mathrm{p}<0.05{ }^{* * *} \mathrm{p}<0.001$ 
Table A.5: Participants/Non-Participants

\begin{tabular}{|c|c|c|c|c|c|c|}
\hline & $\begin{array}{c}\text { Participants } \\
2012-13 \\
\end{array}$ & $\begin{array}{c}\text { Non-Participants } \\
2012-13 \\
\end{array}$ & t-test & $\begin{array}{c}\text { Participants } \\
2017-18 \\
\end{array}$ & $\begin{array}{c}\text { Non-Participants } \\
2017-18 \\
\end{array}$ & t-test \\
\hline Age & $\begin{array}{r}10.34 \\
(0.03)\end{array}$ & $\begin{array}{r}11.20 \\
(0.03)\end{array}$ & 0.00 & $\begin{array}{r}10.74 \\
(0.05)\end{array}$ & $\begin{array}{r}10.70 \\
(0.03\end{array}$ & 0.51 \\
\hline Female & 0.52 & 0.49 & 0.50 & 0.49 & 0.51 & 0.30 \\
\hline Black & 0.39 & 0.43 & 0.20 & 0.19 & 0.55 & 0.00 \\
\hline White & 0.10 & 0.10 & 0.99 & 0.04 & 0.14 & 0.00 \\
\hline Other & 0.01 & 0.00 & 0.51 & 0.00 & 0.01 & 0.36 \\
\hline Household Income (0-15k) & 0.29 & 0.27 & 0.60 & 0.31 & 0.26 & 0.01 \\
\hline Household Income (16k-35k) & 0.32 & 0.23 & 0.00 & 0.26 & 0.27 & 0.78 \\
\hline Household Income (36k-60k) & 0.10 & 0.15 & 0.02 & 0.09 & 0.17 & 0.00 \\
\hline Household Income $(60 \mathrm{k}+)$ & 0.09 & 0.12 & 0.18 & 0.02 & 0.17 & 0.00 \\
\hline Mother Edu (Less than High School) & 0.15 & 0.13 & 0.34 & 0.23 & 0.08 & 0.00 \\
\hline Mother Edu (High School) & 0.31 & 0.37 & 0.06 & 0.34 & 0.40 & 0.01 \\
\hline Mother Edu (College) & 0.29 & 0.30 & 0.74 & 0.13 & 0.41 & 0.00 \\
\hline Cog Pre-Assess. & $\begin{array}{c}0.39 \\
(0.01)\end{array}$ & $\begin{array}{c}0.41 \\
(0.01)\end{array}$ & 0.18 & $\begin{array}{c}0.33 \\
(0.01)\end{array}$ & $\begin{array}{l}0.44 \\
(0.01\end{array}$ & 0.00 \\
\hline Non-Cog Pre-Assess. & $\begin{array}{c}0.53 \\
(0.01)\end{array}$ & $\begin{array}{c}0.60 \\
(0.01)\end{array}$ & 0.00 & $\begin{array}{c}0.58 \\
(0.01)\end{array}$ & $\begin{array}{l}0.59 \\
(0.01\end{array}$ & 0.12 \\
\hline $\mathrm{N}$ & 275 & 1186 & & 647 & 1314 & \\
\hline
\end{tabular}

Note: The table reports summary statistics for experiment participants and non-participants by wave. Standard errors are in parentheses. The t-test columns report the p-value resulting from a t-test comparing participants to non-participants in each wave. 
Table A.6: Treatment Effects Disaggregated: Wave 2012-13

\begin{tabular}{|c|c|c|c|c|c|c|c|c|}
\hline & $\begin{array}{c}(1) \\
\text { Time Pref }\end{array}$ & $\begin{array}{c}(2) \\
\text { Time Pref }\end{array}$ & $\begin{array}{c}(3) \\
\text { Time Pref }\end{array}$ & $\begin{array}{c}(4) \\
\text { Time Pref }\end{array}$ & $\begin{array}{c}(5) \\
\text { Always Now }\end{array}$ & $\begin{array}{c}\text { (6) } \\
\text { Always Now }\end{array}$ & $\begin{array}{c}(7) \\
\text { Always Now }\end{array}$ & $\begin{array}{c}(8) \\
\text { Always Now }\end{array}$ \\
\hline In Kinderprep & $\begin{array}{c}0.03 \\
(0.13)\end{array}$ & $\begin{array}{c}0.04 \\
(0.13)\end{array}$ & $\begin{array}{c}0.03 \\
(0.15)\end{array}$ & $\begin{array}{l}-0.03 \\
(0.14)\end{array}$ & $\begin{array}{l}-0.03 \\
(0.06)\end{array}$ & $\begin{array}{l}-0.03 \\
(0.06)\end{array}$ & $\begin{array}{l}-0.03 \\
(0.07)\end{array}$ & $\begin{array}{l}-0.02 \\
(0.07)\end{array}$ \\
\hline In PA Cash & $\begin{array}{c}0.01 \\
(0.14)\end{array}$ & $\begin{array}{c}0.03 \\
(0.14)\end{array}$ & $\begin{array}{c}0.04 \\
(0.14)\end{array}$ & $\begin{array}{c}0.08 \\
(0.14)\end{array}$ & $\begin{array}{l}-0.01 \\
(0.07)\end{array}$ & $\begin{array}{l}-0.01 \\
(0.07)\end{array}$ & $\begin{array}{l}-0.02 \\
(0.07)\end{array}$ & $\begin{array}{l}-0.03 \\
(0.07)\end{array}$ \\
\hline In PA College & $\begin{array}{l}-0.22 \\
(0.13)\end{array}$ & $\begin{array}{l}-0.19 \\
(0.13)\end{array}$ & $\begin{array}{l}-0.12 \\
(0.14)\end{array}$ & $\begin{array}{l}-0.19 \\
(0.14)\end{array}$ & $\begin{array}{c}0.05 \\
(0.07)\end{array}$ & $\begin{array}{c}0.03 \\
(0.07)\end{array}$ & $\begin{array}{l}-0.01 \\
(0.07)\end{array}$ & $\begin{array}{c}0.02 \\
(0.08)\end{array}$ \\
\hline In PK Literacy & $\begin{array}{l}-0.24 \\
(0.13)\end{array}$ & $\begin{array}{l}-0.21 \\
(0.14)\end{array}$ & $\begin{array}{l}-0.14 \\
(0.15)\end{array}$ & $\begin{array}{l}-0.12 \\
(0.15)\end{array}$ & $\begin{array}{c}0.04 \\
(0.07)\end{array}$ & $\begin{array}{c}0.03 \\
(0.07)\end{array}$ & $\begin{array}{l}-0.01 \\
(0.08)\end{array}$ & $\begin{array}{l}-0.00 \\
(0.08)\end{array}$ \\
\hline In PK Tools & $\begin{array}{l}-0.07 \\
(0.15)\end{array}$ & $\begin{array}{l}-0.05 \\
(0.15)\end{array}$ & $\begin{array}{c}0.01 \\
(0.16)\end{array}$ & $\begin{array}{c}0.02 \\
(0.17)\end{array}$ & $\begin{array}{c}0.04 \\
(0.07)\end{array}$ & $\begin{array}{c}0.03 \\
(0.07)\end{array}$ & $\begin{array}{c}0.00 \\
(0.08)\end{array}$ & $\begin{array}{c}0.01 \\
(0.08)\end{array}$ \\
\hline In $\operatorname{Cog} \mathrm{X}$ & $\begin{array}{c}0.08 \\
(0.10)\end{array}$ & $\begin{array}{c}0.10 \\
(0.10)\end{array}$ & $\begin{array}{c}0.10 \\
(0.11)\end{array}$ & $\begin{array}{c}0.11 \\
(0.11)\end{array}$ & $\begin{array}{l}-0.05 \\
(0.05)\end{array}$ & $\begin{array}{l}-0.06 \\
(0.05)\end{array}$ & $\begin{array}{l}-0.06 \\
(0.05)\end{array}$ & $\begin{array}{l}-0.06 \\
(0.05)\end{array}$ \\
\hline Child Age (in Years) & $\begin{array}{c}0.05 \\
(0.09)\end{array}$ & $\begin{array}{c}0.04 \\
(0.09)\end{array}$ & $\begin{array}{c}0.02 \\
(0.12)\end{array}$ & $\begin{array}{c}0.05 \\
(0.12)\end{array}$ & $\begin{array}{l}-0.05 \\
(0.04)\end{array}$ & $\begin{array}{l}-0.05 \\
(0.04)\end{array}$ & $\begin{array}{l}-0.07 \\
(0.06)\end{array}$ & $\begin{array}{l}-0.08 \\
(0.06)\end{array}$ \\
\hline Child Gender $($ Female $=1)$ & $\begin{array}{c}0.05 \\
(0.07)\end{array}$ & $\begin{array}{c}0.06 \\
(0.07)\end{array}$ & $\begin{array}{c}0.08 \\
(0.07)\end{array}$ & $\begin{array}{c}0.10 \\
(0.07)\end{array}$ & $\begin{array}{l}-0.04 \\
(0.03)\end{array}$ & $\begin{array}{l}-0.04 \\
(0.03)\end{array}$ & $\begin{array}{l}-0.06 \\
(0.03)\end{array}$ & $\begin{array}{l}-0.06 \\
(0.04)\end{array}$ \\
\hline Child Race - White & $\begin{array}{l}-0.05 \\
(0.12)\end{array}$ & $\begin{array}{c}0.01 \\
(0.12)\end{array}$ & $\begin{array}{c}0.03 \\
(0.14)\end{array}$ & $\begin{array}{l}-0.01 \\
(0.14)\end{array}$ & $\begin{array}{c}0.05 \\
(0.06)\end{array}$ & $\begin{array}{c}0.03 \\
(0.06)\end{array}$ & $\begin{array}{c}0.05 \\
(0.06)\end{array}$ & $\begin{array}{c}0.06 \\
(0.06)\end{array}$ \\
\hline Child Race - Black & $\begin{array}{c}-0.27^{* * *} \\
(0.07)\end{array}$ & $\begin{array}{c}-0.27^{* * *} \\
(0.07)\end{array}$ & $\begin{array}{c}-0.28^{* * *} \\
(0.08)\end{array}$ & $\begin{array}{c}-0.31^{* * *} \\
(0.08)\end{array}$ & $\begin{array}{l}0.14^{* * *} \\
(0.04)\end{array}$ & $\begin{array}{c}0.13^{* * *} \\
(0.04)\end{array}$ & $\begin{array}{c}0.16^{* * *} \\
(0.04)\end{array}$ & $\begin{array}{c}0.17^{* * *} \\
(0.04)\end{array}$ \\
\hline Child Race - Other & $\begin{array}{l}-0.21 \\
(0.35)\end{array}$ & $\begin{array}{l}-0.22 \\
(0.35)\end{array}$ & $\begin{array}{l}-0.24 \\
(0.37)\end{array}$ & $\begin{array}{l}-0.24 \\
(0.37)\end{array}$ & $\begin{array}{c}0.21 \\
(0.14)\end{array}$ & $\begin{array}{c}0.23 \\
(0.14)\end{array}$ & $\begin{array}{c}0.27 \\
(0.14)\end{array}$ & $\begin{array}{c}0.27 \\
(0.14)\end{array}$ \\
\hline $\mathrm{R} 2$ & 0.06 & 0.07 & 0.07 & 0.08 & 0.05 & 0.06 & 0.08 & 0.09 \\
\hline $\mathrm{N}$ & 909 & 909 & 817 & 802 & 909 & 909 & 817 & 802 \\
\hline
\end{tabular}

This table reports OLS coefficient estimates of treatment effects on child time preferences for Wave 2013, with treatments disaggregated into individual programs.

All regressions control for age at test date, gender, race, wave year, year of treatment, age at beginning of treatment and years in the program. Hispanic is the reference category for race. Column 2 includes the ses controls household income, mother education, mother age at child birth and birthweight. Column 3 includes controls for cognitive and non-cognitive index scores measured before treatment assignment. The cognitive and non-cognitive indexes are calculated as the mean of the subtests. Column 4 includes a control for child risk preference, evaluated concurrently with time preference. The same specifications are repeated with students always selecting the present time period as the outcome variable.

$* \mathrm{p}<0.10 * * \mathrm{p}<0.05 * * * \mathrm{p}<0.001$ Standard errors are in parentheses. All regressions are clustered at the individual level. 
Table A.7: Treatment Effects Disaggregated: Wave 2017-18

\begin{tabular}{|c|c|c|c|c|c|c|c|c|}
\hline & $\begin{array}{c}(1) \\
\text { Time Pref }\end{array}$ & $\begin{array}{c}(2) \\
\text { Time Pref }\end{array}$ & $\begin{array}{c}(3) \\
\text { Time Pref }\end{array}$ & $\begin{array}{c}(4) \\
\text { Time Pref }\end{array}$ & $\begin{array}{c}(5) \\
\text { Always Now }\end{array}$ & $\begin{array}{c}\text { (6) } \\
\text { Always Now }\end{array}$ & $\begin{array}{c}(7) \\
\text { Always Now }\end{array}$ & $\begin{array}{c}\text { (8) } \\
\text { Always Now }\end{array}$ \\
\hline In Kinderprep & $\begin{array}{c}0.04 \\
(0.15)\end{array}$ & $\begin{array}{c}0.03 \\
(0.15)\end{array}$ & $\begin{array}{l}-0.02 \\
(0.18)\end{array}$ & $\begin{array}{l}-0.05 \\
(0.18)\end{array}$ & $\begin{array}{l}-0.02 \\
(0.04)\end{array}$ & $\begin{array}{l}-0.01 \\
(0.04)\end{array}$ & $\begin{array}{c}0.03 \\
(0.06)\end{array}$ & $\begin{array}{c}0.03 \\
(0.06)\end{array}$ \\
\hline In PA Cash & $\begin{array}{c}0.15 \\
(0.16)\end{array}$ & $\begin{array}{c}0.21 \\
(0.16)\end{array}$ & $\begin{array}{c}0.16 \\
(0.17)\end{array}$ & $\begin{array}{c}0.20 \\
(0.17)\end{array}$ & $\begin{array}{l}-0.04 \\
(0.04)\end{array}$ & $\begin{array}{l}-0.04 \\
(0.04)\end{array}$ & $\begin{array}{l}-0.03 \\
(0.05)\end{array}$ & $\begin{array}{l}-0.04 \\
(0.05)\end{array}$ \\
\hline In PA College & $\begin{array}{l}-0.15 \\
(0.15)\end{array}$ & $\begin{array}{l}-0.15 \\
(0.15)\end{array}$ & $\begin{array}{l}-0.17 \\
(0.17)\end{array}$ & $\begin{array}{l}-0.19 \\
(0.17)\end{array}$ & $\begin{array}{l}-0.06 \\
(0.04)\end{array}$ & $\begin{array}{l}-0.06 \\
(0.04)\end{array}$ & $\begin{array}{l}-0.05 \\
(0.04)\end{array}$ & $\begin{array}{l}-0.05 \\
(0.04)\end{array}$ \\
\hline In PK Literacy & $\begin{array}{c}0.13 \\
(0.22)\end{array}$ & $\begin{array}{c}0.12 \\
(0.22)\end{array}$ & $\begin{array}{c}0.20 \\
(0.24)\end{array}$ & $\begin{array}{c}0.19 \\
(0.24)\end{array}$ & $\begin{array}{l}-0.01 \\
(0.06)\end{array}$ & $\begin{array}{l}-0.00 \\
(0.06)\end{array}$ & $\begin{array}{l}-0.02 \\
(0.07)\end{array}$ & $\begin{array}{l}-0.02 \\
(0.07)\end{array}$ \\
\hline In PK Tools & $\begin{array}{c}0.33 \\
(0.22)\end{array}$ & $\begin{array}{c}0.34 \\
(0.23)\end{array}$ & $\begin{array}{c}0.38 \\
(0.23)\end{array}$ & $\begin{array}{c}0.40 \\
(0.22)\end{array}$ & $\begin{array}{l}-0.02 \\
(0.06)\end{array}$ & $\begin{array}{l}-0.01 \\
(0.06)\end{array}$ & $\begin{array}{l}-0.04 \\
(0.06)\end{array}$ & $\begin{array}{l}-0.04 \\
(0.06)\end{array}$ \\
\hline In $\operatorname{Cog} \mathrm{X}$ & $\begin{array}{l}-0.10 \\
(0.13)\end{array}$ & $\begin{array}{l}-0.09 \\
(0.12)\end{array}$ & $\begin{array}{l}-0.09 \\
(0.14)\end{array}$ & $\begin{array}{l}-0.08 \\
(0.14)\end{array}$ & $\begin{array}{l}-0.01 \\
(0.04)\end{array}$ & $\begin{array}{l}-0.01 \\
(0.04)\end{array}$ & $\begin{array}{l}-0.01 \\
(0.05)\end{array}$ & $\begin{array}{l}-0.01 \\
(0.05)\end{array}$ \\
\hline Child Age (in Years) & $\begin{array}{c}0.20 \\
(0.12)\end{array}$ & $\begin{array}{c}0.18 \\
(0.12)\end{array}$ & $\begin{array}{c}0.10 \\
(0.15)\end{array}$ & $\begin{array}{c}0.09 \\
(0.14)\end{array}$ & $\begin{array}{l}-0.04 \\
(0.04)\end{array}$ & $\begin{array}{l}-0.03 \\
(0.04)\end{array}$ & $\begin{array}{c}0.01 \\
(0.05)\end{array}$ & $\begin{array}{c}0.01 \\
(0.05)\end{array}$ \\
\hline Child Gender $($ Female $=1)$ & $\begin{array}{c}0.07 \\
(0.08)\end{array}$ & $\begin{array}{c}0.07 \\
(0.08)\end{array}$ & $\begin{array}{c}0.01 \\
(0.09)\end{array}$ & $\begin{array}{c}0.02 \\
(0.09)\end{array}$ & $\begin{array}{l}-0.00 \\
(0.03)\end{array}$ & $\begin{array}{l}-0.00 \\
(0.03)\end{array}$ & $\begin{array}{c}0.02 \\
(0.03)\end{array}$ & $\begin{array}{c}0.02 \\
(0.03)\end{array}$ \\
\hline Child Race - White & $\begin{array}{l}-0.16 \\
(0.22)\end{array}$ & $\begin{array}{l}-0.21 \\
(0.22)\end{array}$ & $\begin{array}{l}-0.21 \\
(0.24)\end{array}$ & $\begin{array}{l}-0.21 \\
(0.25)\end{array}$ & $\begin{array}{c}0.03 \\
(0.07)\end{array}$ & $\begin{array}{c}0.05 \\
(0.07)\end{array}$ & $\begin{array}{c}0.05 \\
(0.07)\end{array}$ & $\begin{array}{c}0.05 \\
(0.07)\end{array}$ \\
\hline Child Race - Black & $\begin{array}{l}-0.05 \\
(0.10)\end{array}$ & $\begin{array}{l}-0.03 \\
(0.10)\end{array}$ & $\begin{array}{c}0.06 \\
(0.11)\end{array}$ & $\begin{array}{c}0.07 \\
(0.11)\end{array}$ & $\begin{array}{c}0.00 \\
(0.03)\end{array}$ & $\begin{array}{l}-0.02 \\
(0.03)\end{array}$ & $\begin{array}{l}-0.04 \\
(0.04)\end{array}$ & $\begin{array}{l}-0.04 \\
(0.04)\end{array}$ \\
\hline Child Race - Other & $\begin{array}{l}-0.99 \\
(0.65)\end{array}$ & $\begin{array}{l}-1.01 \\
(0.71)\end{array}$ & $\begin{array}{l}-0.93 \\
(0.73)\end{array}$ & $\begin{array}{l}-1.03 \\
(0.77)\end{array}$ & $\begin{array}{c}0.39 \\
(0.38)\end{array}$ & $\begin{array}{c}0.39 \\
(0.38)\end{array}$ & $\begin{array}{c}0.36 \\
(0.34)\end{array}$ & $\begin{array}{c}0.36 \\
(0.35)\end{array}$ \\
\hline $\mathrm{R} 2$ & 0.05 & 0.07 & 0.09 & 0.11 & 0.03 & 0.04 & 0.06 & 0.06 \\
\hline $\mathrm{N}$ & 593 & 593 & 503 & 501 & 593 & 593 & 503 & 501 \\
\hline
\end{tabular}

This table reports OLS coefficient estimates of treatment effects on child time preferences for Wave 2018, with treatments disaggregated into individual programs.

All regressions control for age at test date, gender, race, wave year, year of treatment, age at beginning of treatment and years in the program. Hispanic is the reference category for race. Column 2 includes the ses controls household income, mother education, mother age at child birth and birthweight. Column 3 includes controls for cognitive and non-cognitive index scores measured before treatment assignment. . The cognitive and non-cognitive indexes are calculated as the mean of the subtests. Column 4 includes a control for child risk preference, evaluated concurrently with time preference. The same specifications are repeated with students always selecting the present time period as the outcome variable.

$* \mathrm{p}<0.10 * * \mathrm{p}<0.05 * * * \mathrm{p}<0.001$ All regressions are clustered at the individual level. 
Table A.8: Inverse Probability Weights: Wave 2012-13

\begin{tabular}{|c|c|c|c|c|c|c|c|c|}
\hline & $\begin{array}{c}(1) \\
\text { Time Pref }\end{array}$ & $\begin{array}{c}(2) \\
\text { Time Pref }\end{array}$ & $\begin{array}{c}(3) \\
\text { Time Pref }\end{array}$ & $\begin{array}{c}(4) \\
\text { Time Pref }\end{array}$ & $\begin{array}{c}(5) \\
\text { Always Now }\end{array}$ & $\begin{array}{c}(6) \\
\text { Always Now }\end{array}$ & $\begin{array}{c}\text { (7) } \\
\text { Always Now }\end{array}$ & $\begin{array}{c}(8) \\
\text { Always Now }\end{array}$ \\
\hline Preschool Dummy & $\begin{array}{c}0.12 \\
(0.12)\end{array}$ & $\begin{array}{c}0.16 \\
(0.12)\end{array}$ & $\begin{array}{c}0.16 \\
(0.13)\end{array}$ & $\begin{array}{c}0.15 \\
(0.13)\end{array}$ & $\begin{array}{l}-0.06 \\
(0.06)\end{array}$ & $\begin{array}{l}-0.08 \\
(0.06)\end{array}$ & $\begin{array}{l}-0.06 \\
(0.06)\end{array}$ & $\begin{array}{l}-0.06 \\
(0.06)\end{array}$ \\
\hline Parent Academy Dummy & $\begin{array}{l}-0.08 \\
(0.14)\end{array}$ & $\begin{array}{l}-0.07 \\
(0.15)\end{array}$ & $\begin{array}{l}-0.09 \\
(0.15)\end{array}$ & $\begin{array}{l}-0.07 \\
(0.15)\end{array}$ & $\begin{array}{c}0.01 \\
(0.07)\end{array}$ & $\begin{array}{c}0.03 \\
(0.07)\end{array}$ & $\begin{array}{c}0.04 \\
(0.08)\end{array}$ & $\begin{array}{c}0.03 \\
(0.08)\end{array}$ \\
\hline Child Age (in Years) & $\begin{array}{l}-0.02 \\
(0.17)\end{array}$ & $\begin{array}{c}0.00 \\
(0.17)\end{array}$ & $\begin{array}{c}0.07 \\
(0.18)\end{array}$ & $\begin{array}{c}0.10 \\
(0.19)\end{array}$ & $\begin{array}{l}-0.00 \\
(0.08)\end{array}$ & $\begin{array}{l}-0.01 \\
(0.08)\end{array}$ & $\begin{array}{l}-0.08 \\
(0.09)\end{array}$ & $\begin{array}{l}-0.10 \\
(0.10)\end{array}$ \\
\hline Child Gender $($ Female $=1)$ & $\begin{array}{c}0.17 \\
(0.11)\end{array}$ & $\begin{array}{c}0.18 \\
(0.11)\end{array}$ & $\begin{array}{c}0.13 \\
(0.12)\end{array}$ & $\begin{array}{c}0.12 \\
(0.12)\end{array}$ & $\begin{array}{l}-0.10 \\
(0.05)\end{array}$ & $\begin{array}{l}-0.10 \\
(0.05)\end{array}$ & $\begin{array}{l}-0.07 \\
(0.06)\end{array}$ & $\begin{array}{l}-0.07 \\
(0.06)\end{array}$ \\
\hline Child Race - White & $\begin{array}{l}-0.18 \\
(0.17)\end{array}$ & $\begin{array}{l}-0.16 \\
(0.18)\end{array}$ & $\begin{array}{l}-0.13 \\
(0.20)\end{array}$ & $\begin{array}{l}-0.16 \\
(0.20)\end{array}$ & $\begin{array}{l}0.16^{*} \\
(0.08)\end{array}$ & $\begin{array}{c}0.15 \\
(0.08)\end{array}$ & $\begin{array}{c}0.15 \\
(0.09)\end{array}$ & $\begin{array}{c}0.17 \\
(0.09)\end{array}$ \\
\hline Child Race - Black & $\begin{array}{c}-0.29^{* *} \\
(0.11)\end{array}$ & $\begin{array}{l}-0.28^{*} \\
(0.11)\end{array}$ & $\begin{array}{c}-0.33^{* *} \\
(0.12)\end{array}$ & $\begin{array}{c}-0.36^{* *} \\
(0.12)\end{array}$ & $\begin{array}{l}0.17^{* *} \\
(0.06)\end{array}$ & $\begin{array}{l}0.14^{*} \\
(0.06)\end{array}$ & $\begin{array}{l}0.16^{*} \\
(0.06)\end{array}$ & $\begin{array}{l}0.18^{* *} \\
(0.07)\end{array}$ \\
\hline Child Race - Other & $\begin{array}{l}-0.02 \\
(0.48)\end{array}$ & $\begin{array}{l}-0.09 \\
(0.46)\end{array}$ & $\begin{array}{l}-0.14 \\
(0.44)\end{array}$ & $\begin{array}{l}-0.15 \\
(0.41)\end{array}$ & $\begin{array}{c}0.09 \\
(0.20)\end{array}$ & $\begin{array}{c}0.13 \\
(0.19)\end{array}$ & $\begin{array}{c}0.17 \\
(0.18)\end{array}$ & $\begin{array}{c}0.17 \\
(0.17)\end{array}$ \\
\hline Mother's Time Pref. & $\begin{array}{c}0.01 \\
(0.05)\end{array}$ & $\begin{array}{c}0.01 \\
(0.05)\end{array}$ & $\begin{array}{c}0.00 \\
(0.06)\end{array}$ & $\begin{array}{c}0.01 \\
(0.06)\end{array}$ & $\begin{array}{l}-0.01 \\
(0.03)\end{array}$ & $\begin{array}{l}-0.01 \\
(0.03)\end{array}$ & $\begin{array}{l}-0.00 \\
(0.03)\end{array}$ & $\begin{array}{l}-0.00 \\
(0.03)\end{array}$ \\
\hline $\mathrm{R} 2$ & 0.07 & 0.09 & 0.11 & 0.14 & 0.07 & 0.10 & 0.13 & 0.14 \\
\hline Test $\mathrm{PK}=\mathrm{PA}$ p-value & 0.18 & 0.13 & 0.10 & 0.15 & 0.34 & 0.16 & 0.18 & 0.22 \\
\hline $\mathrm{N}$ & 408 & 408 & 368 & 359 & 408 & 408 & 368 & 359 \\
\hline
\end{tabular}

This table reports OLS coefficient estimates of treatment effects on child time preferences for Wave 2013, with inverse probability weights. All regressions control for age at test date, gender, race, wave year, year of treatment, age at beginning of treatment and years in the program. Hispanic is the reference category for race. Column 2 includes the ses controls household income, mother education, mother age at child birth and birthweight. Column 3 includes controls for cognitive and non-cognitive index scores measured before treatment assignment. The cognitive and non-cognitive indexes are calculated as the mean of the subtests. Column 4 includes a control for child risk preference, evaluated concurrently with time preference. The same specifications are repeated with students always selecting the present time period as the outcome variable. The row: PK=PA reports the p-value of a chi-squared test of the equality of the coefficients. Standard errors are in parentheses. All regressions are clustered at the individual level.

$* \mathrm{p}<0.10^{* *} \mathrm{p}<0.05^{* * *} \mathrm{p}<0.001$ 
Table A.9: Inverse Probability Weights: Wave 2017-18

\begin{tabular}{|c|c|c|c|c|c|c|c|c|}
\hline & $\begin{array}{c}(1) \\
\text { Time Pref }\end{array}$ & $\begin{array}{c}(2) \\
\text { Time Pref }\end{array}$ & $\begin{array}{c}(3) \\
\text { Time Pref }\end{array}$ & $\begin{array}{c}(4) \\
\text { Time Pref }\end{array}$ & $\begin{array}{c}(5) \\
\text { Always Now }\end{array}$ & $\begin{array}{c}(6) \\
\text { Always Now }\end{array}$ & $\begin{array}{c}\text { (7) } \\
\text { Always Now }\end{array}$ & $\begin{array}{c}(8) \\
\text { Always Now }\end{array}$ \\
\hline Preschool Dummy & $\begin{array}{c}0.06 \\
(0.14)\end{array}$ & $\begin{array}{c}0.08 \\
(0.14)\end{array}$ & $\begin{array}{c}0.06 \\
(0.17)\end{array}$ & $\begin{array}{c}0.08 \\
(0.16)\end{array}$ & $\begin{array}{l}-0.04 \\
(0.05)\end{array}$ & $\begin{array}{l}-0.04 \\
(0.05)\end{array}$ & $\begin{array}{l}-0.04 \\
(0.06)\end{array}$ & $\begin{array}{l}-0.05 \\
(0.06)\end{array}$ \\
\hline Parent Academy Dummy & $\begin{array}{l}-0.01 \\
(0.18)\end{array}$ & $\begin{array}{c}0.04 \\
(0.19)\end{array}$ & $\begin{array}{c}0.01 \\
(0.21)\end{array}$ & $\begin{array}{c}0.03 \\
(0.21)\end{array}$ & $\begin{array}{l}-0.08 \\
(0.05)\end{array}$ & $\begin{array}{l}-0.08 \\
(0.05)\end{array}$ & $\begin{array}{l}-0.10 \\
(0.06)\end{array}$ & $\begin{array}{l}-0.10 \\
(0.06)\end{array}$ \\
\hline Child Age (in Years) & $\begin{array}{c}0.15 \\
(0.21)\end{array}$ & $\begin{array}{c}0.12 \\
(0.21)\end{array}$ & $\begin{array}{l}-0.11 \\
(0.27)\end{array}$ & $\begin{array}{l}-0.11 \\
(0.26)\end{array}$ & $\begin{array}{l}-0.03 \\
(0.07)\end{array}$ & $\begin{array}{l}-0.03 \\
(0.07)\end{array}$ & $\begin{array}{c}0.03 \\
(0.09)\end{array}$ & $\begin{array}{c}0.04 \\
(0.08)\end{array}$ \\
\hline Child Gender $($ Female $=1)$ & $\begin{array}{c}0.05 \\
(0.12)\end{array}$ & $\begin{array}{c}0.04 \\
(0.12)\end{array}$ & $\begin{array}{c}0.07 \\
(0.15)\end{array}$ & $\begin{array}{c}0.07 \\
(0.15)\end{array}$ & $\begin{array}{c}0.00 \\
(0.04)\end{array}$ & $\begin{array}{c}0.00 \\
(0.04)\end{array}$ & $\begin{array}{l}-0.01 \\
(0.05)\end{array}$ & $\begin{array}{l}-0.01 \\
(0.05)\end{array}$ \\
\hline Child Race - White & $\begin{array}{l}-0.24 \\
(0.30)\end{array}$ & $\begin{array}{l}-0.26 \\
(0.31)\end{array}$ & $\begin{array}{l}-0.25 \\
(0.34)\end{array}$ & $\begin{array}{l}-0.25 \\
(0.34)\end{array}$ & $\begin{array}{c}0.06 \\
(0.09)\end{array}$ & $\begin{array}{c}0.06 \\
(0.10)\end{array}$ & $\begin{array}{c}0.05 \\
(0.10)\end{array}$ & $\begin{array}{c}0.05 \\
(0.11)\end{array}$ \\
\hline Child Race - Black & $\begin{array}{l}-0.17 \\
(0.14)\end{array}$ & $\begin{array}{l}-0.10 \\
(0.14)\end{array}$ & $\begin{array}{l}-0.01 \\
(0.17)\end{array}$ & $\begin{array}{c}0.00 \\
(0.16)\end{array}$ & $\begin{array}{c}0.05 \\
(0.04)\end{array}$ & $\begin{array}{c}0.02 \\
(0.05)\end{array}$ & $\begin{array}{c}0.01 \\
(0.05)\end{array}$ & $\begin{array}{c}0.00 \\
(0.05)\end{array}$ \\
\hline Child Race - Other & $\begin{array}{c}-2.09^{* * *} \\
(0.20)\end{array}$ & $\begin{array}{c}-2.24^{* * *} \\
(0.22)\end{array}$ & $\begin{array}{c}-1.99^{* * *} \\
(0.33)\end{array}$ & $\begin{array}{c}-2.18^{* * *} \\
(0.32)\end{array}$ & $\begin{array}{c}0.98^{* * *} \\
(0.06)\end{array}$ & $\begin{array}{l}1.03^{* * *} \\
(0.07)\end{array}$ & $\begin{array}{c}0.92^{* * *} \\
(0.09)\end{array}$ & $\begin{array}{c}0.97^{* * *} \\
(0.09)\end{array}$ \\
\hline Mother's Time Pref. & $\begin{array}{l}-0.04 \\
(0.06)\end{array}$ & $\begin{array}{l}-0.04 \\
(0.06)\end{array}$ & $\begin{array}{l}-0.02 \\
(0.07)\end{array}$ & $\begin{array}{l}-0.01 \\
(0.07)\end{array}$ & $\begin{array}{c}0.02 \\
(0.02)\end{array}$ & $\begin{array}{c}0.02 \\
(0.02)\end{array}$ & $\begin{array}{c}0.02 \\
(0.02)\end{array}$ & $\begin{array}{c}0.01 \\
(0.02)\end{array}$ \\
\hline $\mathrm{R} 2$ & 0.05 & 0.06 & 0.09 & 0.10 & 0.09 & 0.11 & 0.15 & 0.16 \\
\hline Test $\mathrm{PK}=\mathrm{PA}$ p-value & 0.70 & 0.81 & 0.81 & 0.81 & 0.37 & 0.37 & 0.29 & 0.31 \\
\hline $\mathrm{N}$ & 317 & 317 & 273 & 272 & 317 & 317 & 273 & 272 \\
\hline
\end{tabular}

This table reports OLS coefficient estimates of treatment effects on child time preferences for Wave 2018, with inverse probability weights. All regressions control for age at test date, gender, race, wave year, year of treatment, age at beginning of treatment and years in the program. Hispanic is the reference category for race. Column 2 includes the ses controls household income, mother education, mother age at child birth and birthweight. Column 3 includes controls for cognitive and non-cognitive index scores measured before treatment assignment. . The cognitive and non-cognitive indexes are calculated as the mean of the subtests. Column 4 includes a control for child risk preference, evaluated concurrently with time preference. The same specifications are repeated with students always selecting the present time period as the outcome variable. The row ${ }^{--}{ }^{-} \mathrm{PK}^{-\mathrm{PA}^{---}}$; reports the p-value of a chi-squared test of the equality of the coefficients. Standard errors are in parentheses. All regressions are clustered at the individual level.

$* \mathrm{p}<0.10^{* *} \mathrm{p}<0.05^{* * *} \mathrm{p}<0.001$ 
Table A.10: Marshmallow Test

\begin{tabular}{|c|c|c|c|c|c|c|}
\hline & $\begin{array}{c}(1) \\
\text { Marshmallow }\end{array}$ & $\begin{array}{c}(2) \\
\text { Marshmallow }\end{array}$ & $\begin{array}{c}(3) \\
\text { Marshmallow }\end{array}$ & $\begin{array}{c}(4) \\
\text { Marshmallow }\end{array}$ & $\begin{array}{c}(5) \\
\text { Marshmallow }\end{array}$ & $\begin{array}{c}(6) \\
\text { Marshmallow }\end{array}$ \\
\hline Child Age (in Years) & $\begin{array}{c}5.27 \\
(5.34)\end{array}$ & $\begin{array}{c}3.20 \\
(5.40)\end{array}$ & $\begin{array}{c}3.25 \\
(5.57)\end{array}$ & $\begin{array}{c}4.93 \\
(6.19)\end{array}$ & $\begin{array}{c}6.32 \\
(6.82)\end{array}$ & $\begin{array}{c}5.65 \\
(5.48)\end{array}$ \\
\hline Child Gender $($ Female $=1)$ & $\begin{array}{c}3.37 \\
(8.32)\end{array}$ & $\begin{array}{c}3.11 \\
(8.29)\end{array}$ & $\begin{array}{c}1.46 \\
(8.42)\end{array}$ & $\begin{array}{c}4.95 \\
(8.88)\end{array}$ & $\begin{array}{l}-13.39 \\
(10.93)\end{array}$ & $\begin{array}{c}3.10 \\
(8.40)\end{array}$ \\
\hline Child Race - White & $\begin{array}{c}13.48 \\
(13.31)\end{array}$ & $\begin{array}{l}14.80 \\
(13.20)\end{array}$ & $\begin{array}{c}8.86 \\
(13.60)\end{array}$ & $\begin{array}{l}17.30 \\
(14.34)\end{array}$ & $\begin{array}{c}9.01 \\
(18.02)\end{array}$ & $\begin{array}{c}11.87 \\
(13.40)\end{array}$ \\
\hline Child Race - Black & $\begin{array}{l}-9.44 \\
(8.89)\end{array}$ & $\begin{array}{l}-10.57 \\
(9.05)\end{array}$ & $\begin{array}{l}-11.54 \\
(9.00)\end{array}$ & $\begin{array}{l}-4.03 \\
(9.89)\end{array}$ & $\begin{array}{l}-26.37^{*} \\
(12.05)\end{array}$ & $\begin{array}{l}-10.03 \\
(8.96)\end{array}$ \\
\hline Child Race - Other & $\begin{array}{c}20.20 \\
(33.48)\end{array}$ & $\begin{array}{l}12.27 \\
(38.36)\end{array}$ & $\begin{array}{c}20.74 \\
(33.99)\end{array}$ & $\begin{array}{c}26.38 \\
(32.95)\end{array}$ & $\begin{array}{l}-13.38 \\
(39.35)\end{array}$ & $\begin{array}{l}19.67 \\
(33.32)\end{array}$ \\
\hline Preschool Dummy & & & & & & $\begin{array}{l}-2.44 \\
(9.63)\end{array}$ \\
\hline Parent Academy Dummy & & & & & & $\begin{array}{l}-2.65 \\
(13.50)\end{array}$ \\
\hline $\mathrm{R} 2$ & 0.02 & 0.04 & 0.03 & 0.03 & 0.03 & 0.02 \\
\hline Test Black=White $p$-value & 0.08 & 0.05 & 0.13 & 0.12 & 0.06 & 0.10 \\
\hline $\mathrm{N}$ & 880 & 880 & 880 & 783 & 531 & 872 \\
\hline
\end{tabular}

This table reports OLS coefficient estimates of preschool treatment effects on seconds waited in a marshmallow task. All regressions control for age at test date, gender and race. Hispanic is the reference category for race. Experimental controls include year of treatment. SES controls include household income, mother education, mother age at child birth and birthweight. Column 3 includes controls for cognitive and non-cognitive index scores measured before treatment assignment. The cognitive and non-cognitive indexes are calculated as the mean of the subtests. Column 4 includes controls for cognitive and non-cognitive index scores assessed within a year of the preference measures. Column 5 includes a control for parent time preference. Column 6 includes a control fortreatment, The row Black v. White reports the p-value of a chi-squared test of the equality of the race coefficients. Standard errors are in parentheses.

$* \mathrm{p}<0.10^{* *} \mathrm{p}<0.05^{* * *} \mathrm{p}<0.001$ 
Table A.11: Consistency by Treatment, Wave

\begin{tabular}{lcc}
\hline \hline & $(1)$ & $(2)$ \\
& Consistent, 2013 & Consistent, 2018 \\
\hline Preschool Dummy & $-0.08^{*}$ & -0.08 \\
& $(0.04)$ & $(0.05)$ \\
Parent Academy Dummy & -0.03 & -0.12 \\
& $(0.05)$ & $(0.07)$ \\
Child Age (in Years) & -0.12 & -0.09 \\
& $(0.06)$ & $(0.07)$ \\
Child Gender (Female=1) & -0.04 & 0.03 \\
& $(0.03)$ & $(0.05)$ \\
Child Race - White & $0.16^{* *}$ & -0.00 \\
& $(0.06)$ & $(0.12)$ \\
Child Race - Black & $0.09^{*}$ & 0.03 \\
& $(0.04)$ & $(0.06)$ \\
Child Race - Other & 0.11 & $0.55^{* * *}$ \\
& $(0.12)$ & $(0.08)$ \\
\hline R2 & 0.06 & 0.07 \\
Test PK=PA p-value & 0.39 & 0.55 \\
N & 795 & 490 \\
\hline \hline
\end{tabular}

This table reports OLS coefficient estimates of preschool treatment effects on a dummy for consistency in the time preference response. All regressions control for age at test date, gender, race, wave year, year of treatment, age at beginning of treatment and total years in the program. Ses controls include household income, mother education, mother age at child birth and birthweight. Regressions also control for cognitive and non-cognitive indexes, calculated as the mean of the subtests, and child risk preference, evaluated concurrently with time preference. The row ${ }^{-} \mathrm{PK}=\mathrm{PA}-\mathrm{reports}$ the $\mathrm{p}-$ value of a chi-squared test of the equality of the : coefficients. Standard errors are in parentheses. All regressions are clustered at the individual level.

$* \mathrm{p}<0.10 * * \mathrm{p}<0.05 * * * \mathrm{p}<0.001$ 
Figure A1: Flow Diagram of Participants

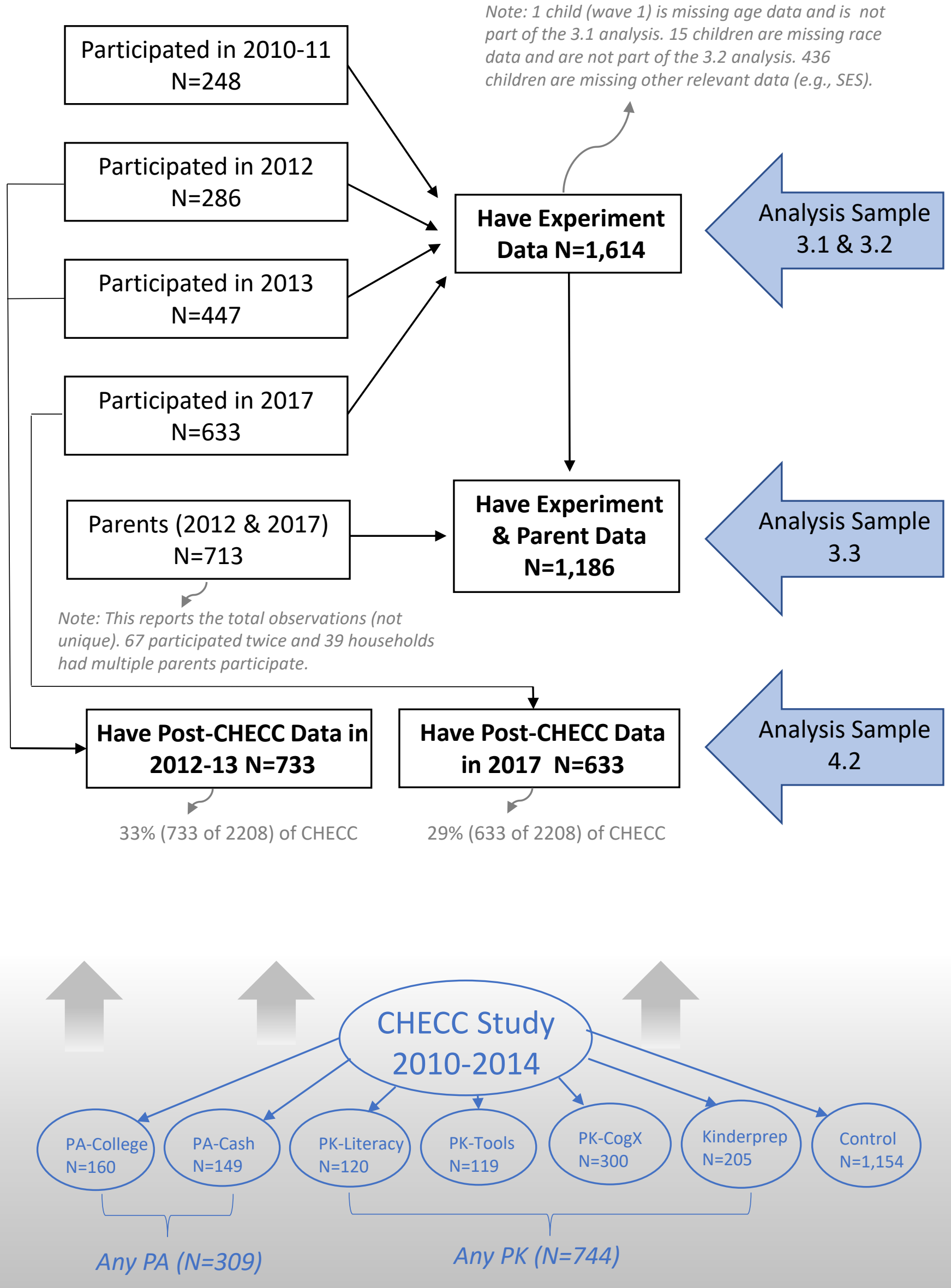


Figure A.2: Histogram of Parent Decisions
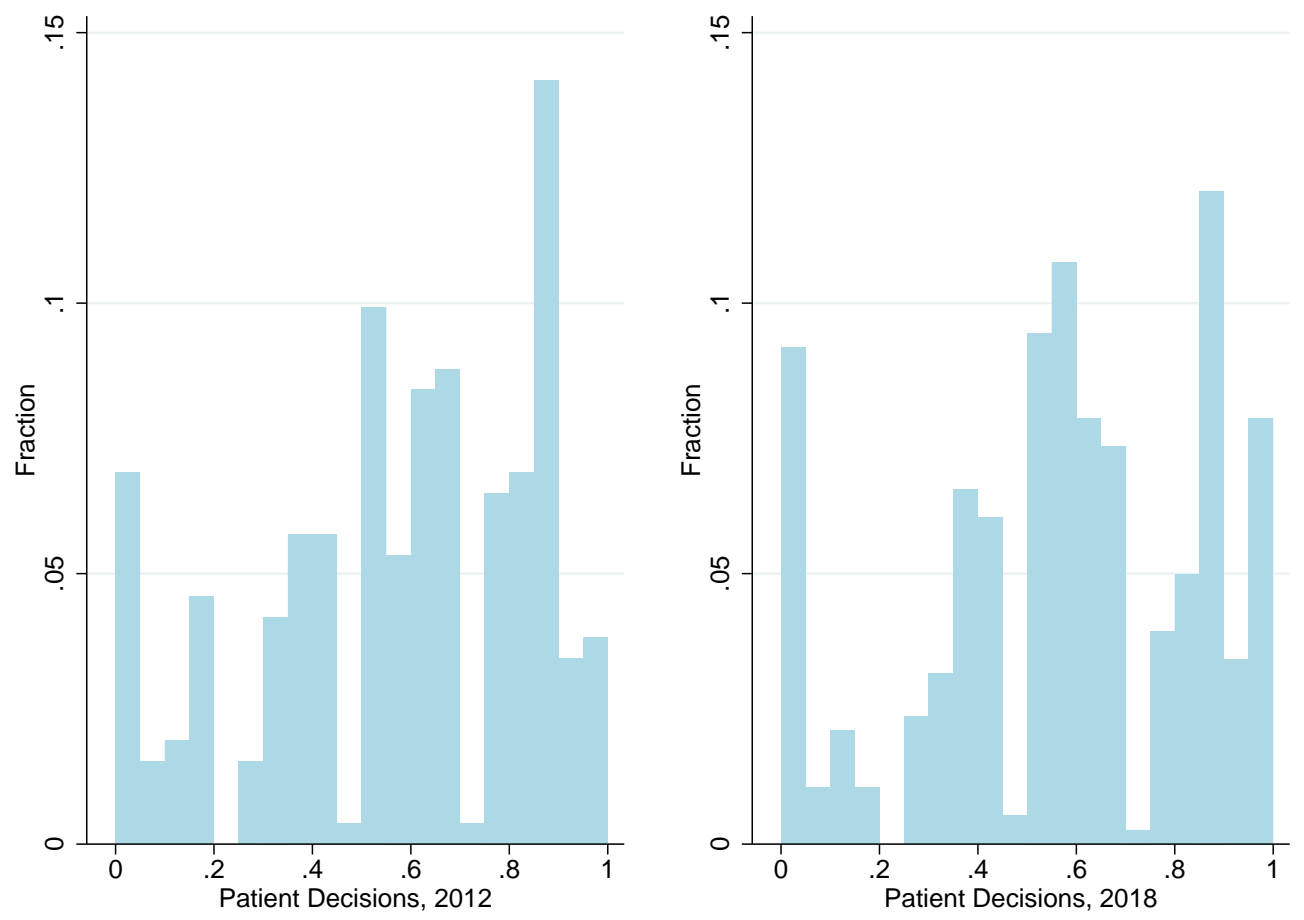


\title{
Appendix - For Online Publication Only
}

\author{
Time Preference Elicitation: Children Ages 3-5
}

\section{$\underline{\text { Instructions }}$}

Now you are going to make some choices about candies. I will show you plates of candies and you will decide which plate you want. Some plates you choose, you can have TODAY, but some plates you choose you can have TOMORROW. I am going to put each plate you choose inside this box. At the end, you will CLOSE YOUR EYES and pick ONE plate from the box and that will be the plate you get to take home.

Okay, let's start!

If you pick THIS plate (point to plate with 4), you could have it at the end of school TODAY.

If you pick THIS plate (point to plate with 5), you could have it at the end of school TOMORROW.

- Quiz \#1-> Can you tell me, if you pick THIS plate (point to plate with 4), when can you have it, today or tomorrow? (Yes/No, if you pick THIS plate you can have it today.)

- Quiz \#2 -> Can you tell me, if you pick THIS plate (point to plate with 5), when can you have it, today or tomorrow? (Yes/No, if you pick THIS plate you can have it tomorrow)

Okay, which plate do you want, this one TODAY or this one TOMORROW?

Okay, now I will put the plate you picked in the box. Let's play again!

If you pick THIS plate (point to plate with 4), you could have it at the end of school TODAY.

If you pick THIS plate (point to plate with 6), you could have it at the end of school TOMORROW.

- Quiz \#1-> Can you tell me, if you pick THIS plate (point to plate with 4), when can you have it, today or tomorrow? (Yes/No, if you pick THIS plate you can have it today.)

- Quiz \#2 -> Can you tell me, if you pick THIS plate (point to plate with 6), when can you have it, today or tomorrow? (Yes/No, if you pick THIS plate you can have it tomorrow)

Okay, which plate do you want, this one TODAY or this one TOMORROW?

If you pick THIS plate (point to plate with 4), you could have it at the end of school TODAY. 


\section{If you pick THIS plate (point to plate with 7), you could have it at the end of school TOMORROW.}

- Quiz \#1-> Can you tell me, if you pick THIS plate (point to plate with 4), when can you have it, today or tomorrow? (Yes/No, if you pick THIS plate you can have it today.)

- Quiz \#2 -> Can you tell me, if you pick THIS plate (point to plate with 7), when can you have it, today or tomorrow? (Yes/No, if you pick THIS plate you can have it tomorrow)

Okay, which plate do you want, this one TODAY or this one TOMORROW?

Okay, now I will put the plate you picked in the box. Let's play again!

If you pick THIS plate (point to plate with 4), you could have it at the end of school TODAY.

If you pick THIS plate (point to plate with 8), you could have it at the end of school TOMORROW.

- Quiz \#1-> Can you tell me, if you pick THIS plate (point to plate with 4), when can you have it, today or tomorrow? (Yes/No, if you pick THIS plate you can have it today.)

- Quiz \#2 -> Can you tell me, if you pick THIS plate (point to plate with 8), when can you have it, today or tomorrow? (Yes/No, if you pick THIS plate you can have it tomorrow)

Okay, which plate do you want, this one TODAY or this one TOMORROW?

Okay, now I will put the plate you picked in the box.

Okay, now you get to pick which plate you want from the box, go ahead and close your eyes, and get one.

Great, this is the plate you will get to have (TODAY/TOMORROW). I will put it in your (TODAY/TOMORROW) bag.

Thank you for playing! Good job.

\section{Time Preference Elicitation: Children Ages 6-12}

\section{CANDY ACTIVITY}

Now we'll make some choices about candy. There is no right or wrong answer in this game, we just want you to put down what you would actually choose.

There are going to be 4 rounds.

You will decide which plate of candy you want. Some of the plates, you can have TODAY, but some of the plates, you can have TOMORROW. If you get a plate for TODAY, you can take it 
home today after the games are done. If you get a plate for TOMORROW, we will give the plate to your parent with instructions that you can't have it until tomorrow.

At the end of the 4 rounds, only one of the rounds will be the round-that-counts and you will get to take that choice home. At the end, we are going to pick a ball out of this jar that determines which of the 4 rounds will be the round-that-counts. Since you don't know which round will count, you should make your decision in each game as if it is the round that counts.

Here are the candies that we will use (hold up candies).

Here is an example of how to circle your choices. 
Veronica is deciding what to do in Round 1. She is choosing between. 1 Candy TODAY, and 2 Candies TOMORROW. She decides to get 1 Candy TODAY. She circles her answer like:

\section{ROUND 1}

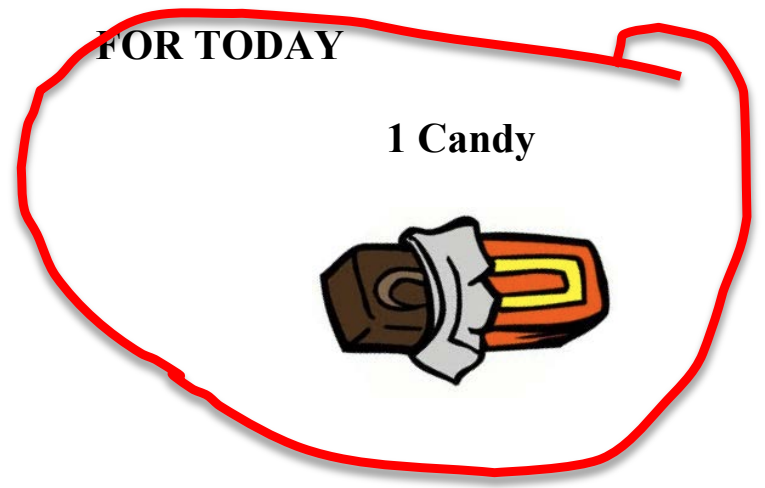

\section{FOR TOMORROW}

\section{Candies}
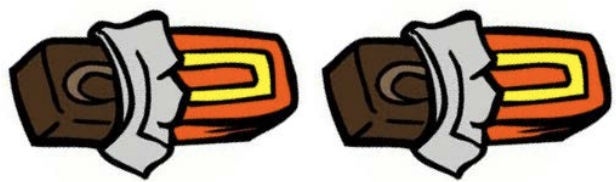

Now Veronica decides what to do in Round 2. She decides between 1 candy today and 3 candies tomorrow. She chooses 3 candies tomorrow. She circles her answer like:

ROUND 2

\section{FOR TODAY}
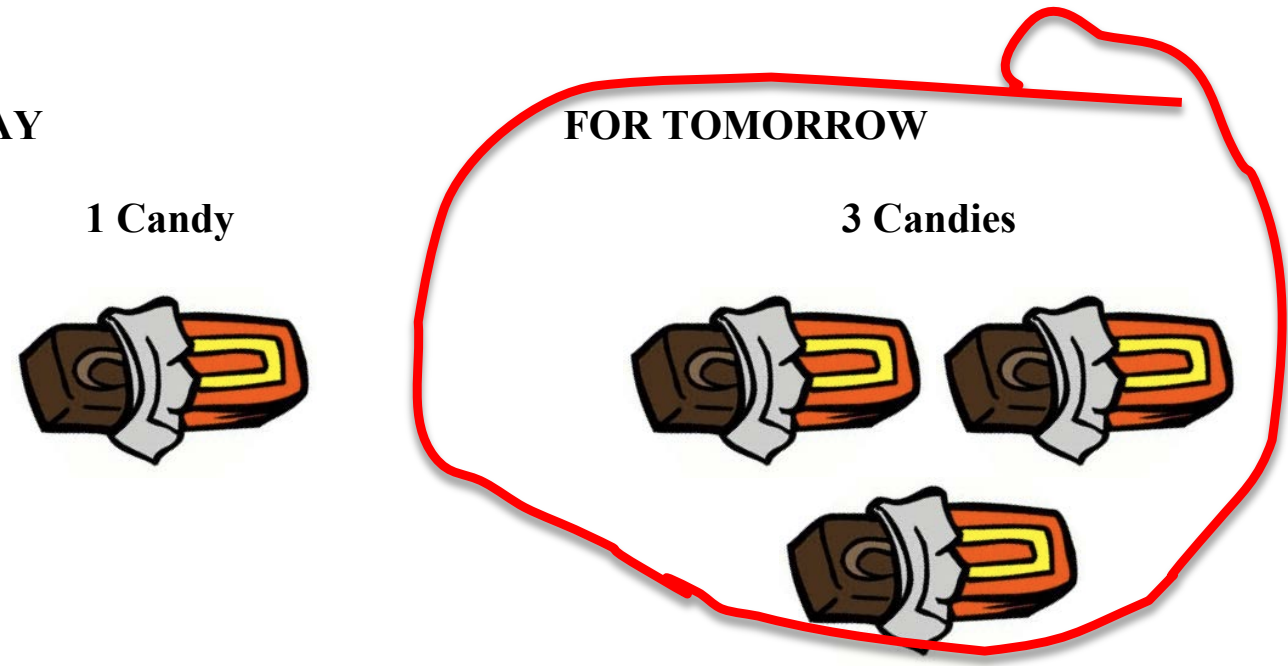

Now I'm going to pass around your activity sheet - for each round, go ahead and circle which candy plate you want.

We'll pick the round that counts at the end. 
Time Preference Elicitation: Parents

\section{ACTIVITY 1}

\section{EARLIER AND LATER ACTIVITY}

For this activity, you will receive some payments in the form of a debit gift card. The gift card can be used at any store Visa, Mastercard, or Discover are accepted. Does anyone have questions about how to use the debit gift card?

We will pass around your debit gift cards now - each person gets one. Please hold on to the cards. The gift cards have $\$ 0$ loaded on them now, but you will present these to the front desk at the end of the activity and the staff will record when and what amount to load on your card. The amount and time depends on the choices you make.

\section{DECISION CARD DECK}

In this activity, you will make 16 choices about when you want to get money deposited on your card, one time is "earlier" and one time is "later." Both the earlier and later times can be different for different decisions. This means you could receive payments as early as today, as late as 10 weeks from now, or possibly other dates in between. The gift card will be ready to use immediately after it is loaded.

You will receive a decision card deck with 16 decision cards. In each decision card, you will make a choice between an amount deposited on your gift card earlier or an amount deposited on your gift card later.

Please select the option you prefer, not what you think anyone might want you to prefer. Please only select one choice per card by checking the box. After you are done, put the finished card face down and begin on the next card. You can't go back to previous choices so think carefully about each choice. Note that the amounts and the "Now" and "Later" times may change with each new card, so pay close attention to them.

\section{CHOICE-THAT-COUNTS}

Only one of your cards will be the choice-that-counts. When we are finished with all activities, you will bring all of your decision cards and your gift card up to the Research Assistant. The Research Assistant will shuffle up your cards and present them to you face down like this (demonstrate). You will then pick one of the cards from the deck, and this will be the one that is paid out. Since all decisions are equally likely to be chosen, you should make each decision as if it will be the decision you will actually receive; in other words, choose the outcome you really want.

\section{PAYMENTS}

The "earlier" and "later" payment will be in the form of deposits into your debit gift card. If you choose to receive money today, your deposit will be made within 2 hours. If you choose to receive money at a future date, we will be depositing the money on the day specified by 12 noon. We will give you a call as soon as your card is loaded. 
As a reminder to you, you will receive a "receipt" that lets you know the days and times your deposits are scheduled to arrive. If you don't get a payment on the date on your receipt, or you lose your card, please contact us right away and we will assist you. If you need this method explained again please raise your hand.

\section{PRACTICE ROUND WITH CANDY}

First we will do a practice round with candy. The "Now" time will be right away, and the "Later" time will be at the end of the activity session, this is about 1 hour from now. If you get a candy "Now," you can go ahead and eat it. You will make 3 choices.

After you are done with each choice, place the cards face down and a Research Assistant will come by to have you draw out one card, that will be the choice-that-counts from your set. If you selected candy "Now" on that card, you will pick out the candy from this basket. If you selected candy "Later" on that card, you will present your card to the desk in front and pick up the candy on your way out.

\section{PROCEED TO ACTIVITY}

We are going to pass out your decision card deck now. Different from the candy round, you will get to find out which choice is the "choice that counts" at the very end of all the activities. 
Please pick either Option A or Option B.

\begin{tabular}{|l|}
\hline$\square$ OPTION A - EARLIER \\
"I'd rather get \$20 \\
$\mathbf{5}$ weeks from \\
today."
\end{tabular}

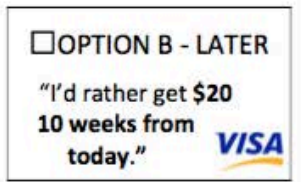

Decision 9

Please pick either Option A or Option B.

\begin{tabular}{|l|}
\hline DOPTION A - EARLIER \\
"I'd rather get \$18 \\
$\mathbf{5}$ weeks from \\
today."
\end{tabular}

口OPTION B - LATER
"I’d rather get \$20
10 weeks from VISA
today."

Decision 11

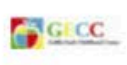

Please pick either

Option A or Option B.

$\square$ OPTION A - EARLIER
"I'd rather get \$14
$\mathbf{5}$ weeks from
today."

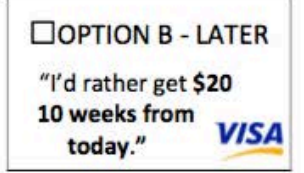

Decision 13

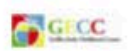

Please pick either

Option A or Option B.

\begin{tabular}{|l|}
\hline OOPTION A - EARLIER \\
"I'd rather get \$10 \\
$\mathbf{5}$ weeks from \\
today."
\end{tabular}
$\square$ OPTION B - LATER
"l'd rather get $\$ 20$
10 weeks from today." VISA

Decision 15
Please pick either Option A or Option B.

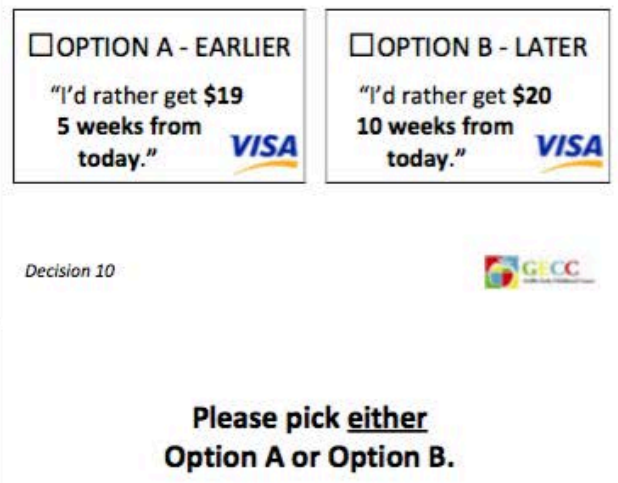

$\square$ OPTION B - LATER

"l'd rather get $\$ \mathbf{2 0}$

10 weeks from today." VISA

Decision 12

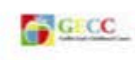

Please pick either Option A or Option B.

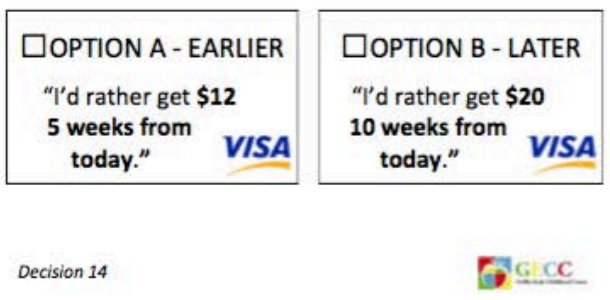

Please pick either Option A or Option B.

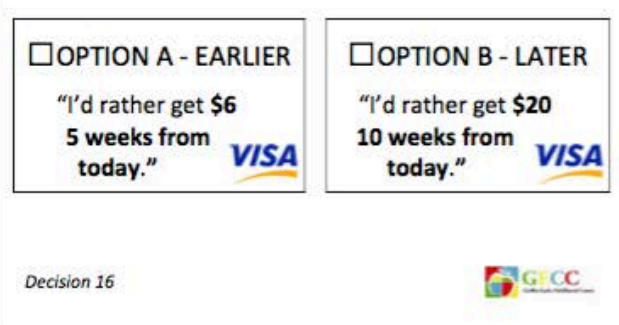

